Aus der Klinik für Gastroenterologie und gastrointestinale Onkologie (Prof. Dr. med. V. Ellenrieder) der Medizinischen Fakultät der Universität Göttingen

\title{
Evaluation der sonographischen Gallenblasenwanddicke als neuer nicht- invasiver Marker für das Vorliegen von Ösophagusvarizen
}

\author{
INAUGURAL-DISSERTATION \\ zur Erlangung des Doktorgrades \\ der Medizinischen Fakultät der \\ Georg-August-Universität zu Göttingen
}

vorgelegt von

Birgit Helga Tsaknakis (geb. Hannemann)

aus

Einbeck

Göttingen 2019 
Dekan:

Referent/in

Ko-Referent/in:

Drittreferent/in:
Prof. Dr. rer. nat. H.K. Kroemer

PD Dr. med. S. Kunsch

Datum der mündlichen Prüfung: 
Hiermit erkläre ich, die Dissertation mit dem Titel "Evaluation der sonographischen Gallenblasenwanddicke als neuer nicht-invasiver Marker für das Vorliegen von Ösophagusvarizen" eigenständig angefertigt und keine anderen als die von mir angegebenen Quellen und Hilfsmittel verwendet zu haben.

Göttingen, den 7. Juli 2019 
Daten, auf denen diese Arbeit basiert, wurden teilweise an folgender Stelle veröffentlicht: „Gall bladder wall thickening as non-invasive screening parameter for esophageal varices - a comparative endoscopic - sonographic study“ in BMC Gastroenterol. 2018 Aug 2;18(1):123.

Göttingen, den 7. Juli 2019

(Unterschrift) 


\section{Inhaltsverzeichnis}

Abbildungsverzeichnis ............................................................................................. III

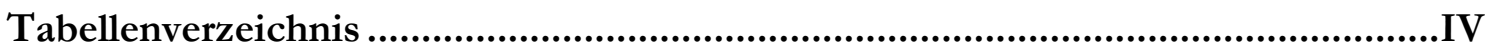

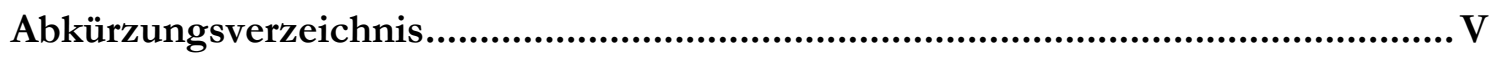

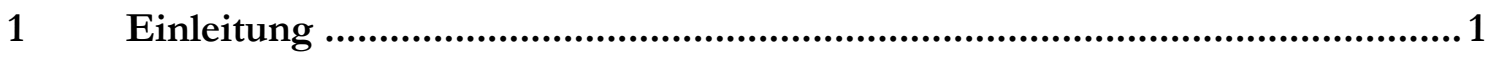

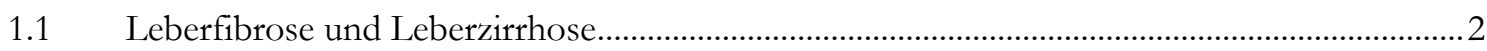

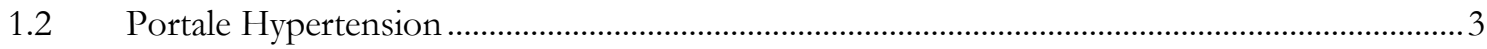

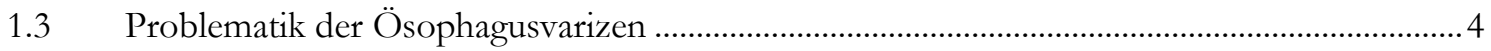

$1.4 \quad$ Laborchemische Aspekte in Assoziation mit Ösophagusvarizen..................................................5

1.5 Sonographische Aspekte in Assoziation mit Ösophagusvarizen...................................................

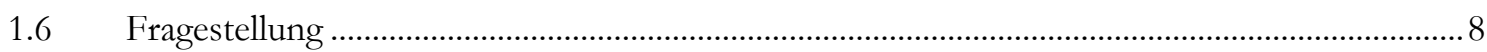

$2 \quad$ Material und Methoden .........................................................................

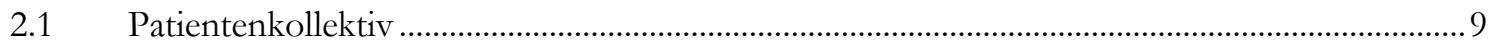

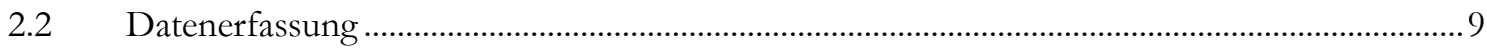

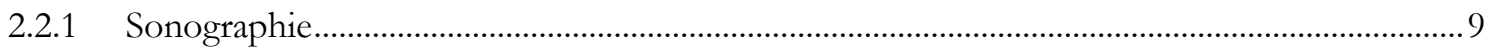

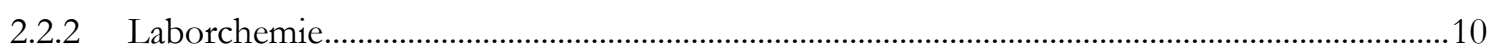

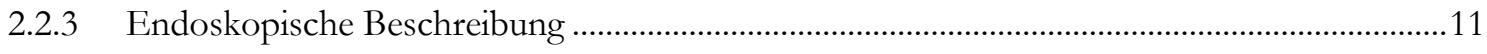

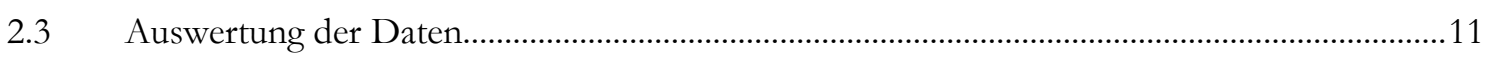

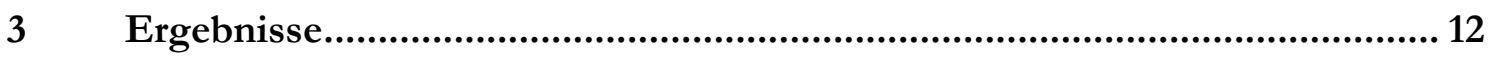

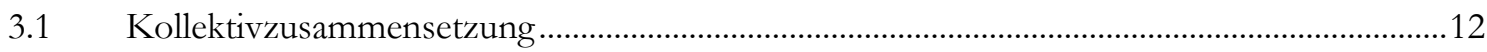

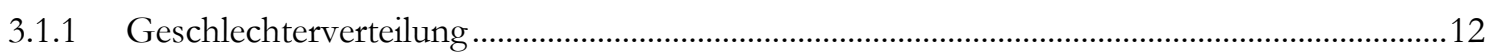

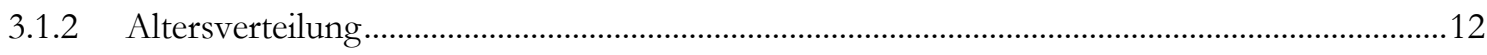

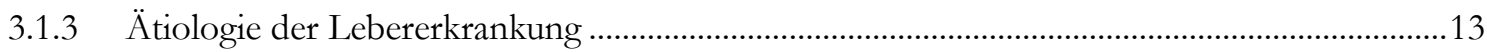

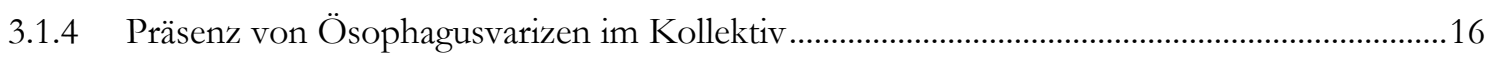

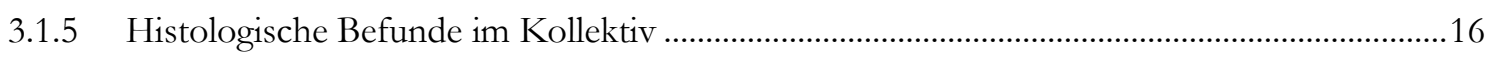

3.2 Assoziation sonographischer Parameter mit dem Vorliegen von Ösophagusvarizen ............16

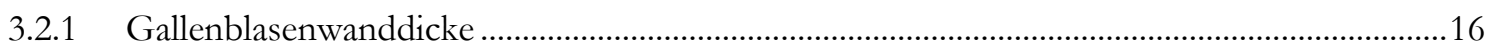

3.2.1.1 Auswertung der Gallenblasenwanddicke abhängig von vorhandenen

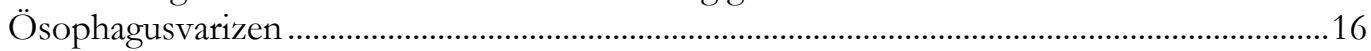

3.2.1.2 Auswertung einer Gallenblasenwandverdickung in Assoziation mit anderen Faktoren ........18

3.2.2 Gallenblasengröße bestimmt in maximaler Längs- und Querausdehnung ...............................20

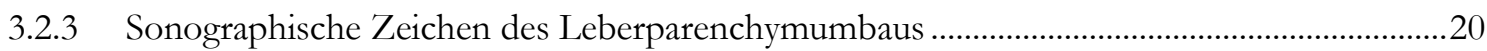

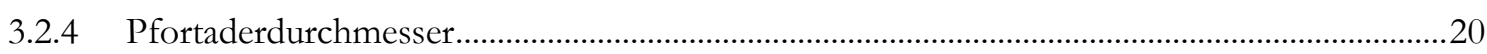

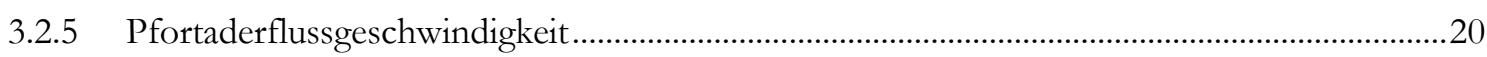

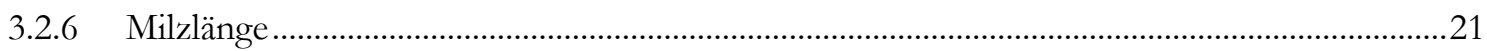

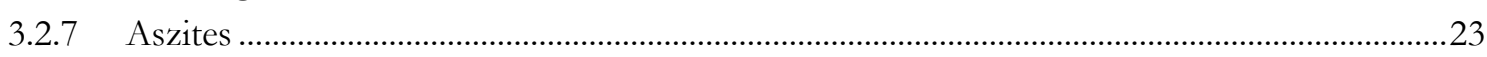

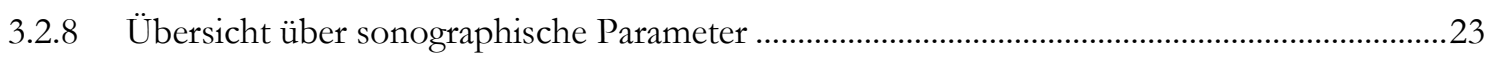


3.3 Assoziation laborchenischer Werte mit dem Vorhandensein von Ösophagusvarizen..........23

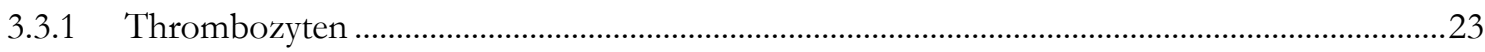

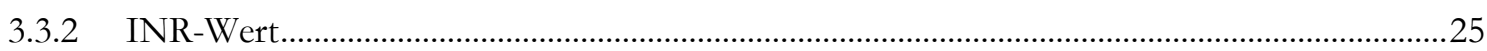

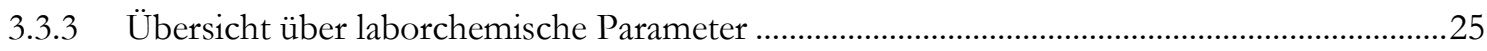

3.4 Assoziation hypertensive Gastropathie mit dem Vorhandensein von

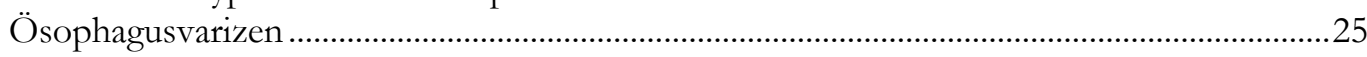

3.5 Assoziation des Child-Pugh-Score mit dem Vorhandensein von Ösophagusvarizen ............25

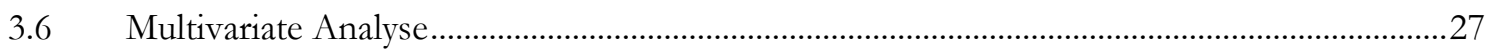

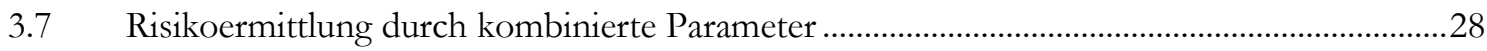

3.7.1 Wahrscheinlichkeit von Ösophagusvarizen abhängig von kombinierten Parametern..........28

3.7.2 Wahrscheinlichkeit von Ösophhagusvarizen nach dem Quotienten von Giannini ...............29

3.7.3 Wahrscheinlichkeit von Ösophhagusvarizen durch die Bildung eines Quotienten aus Thrombozytenzahl und Gallenblasenwanddicke …………......................................................2

3.8 Übersicht der einzelnen und kombinierten Parameter im Vergleich ..........................................30

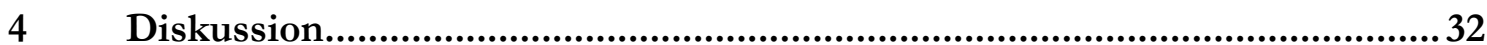

4.1 Untersuchung der Gallenblasenwanddicke als indikativer Parameter für das Vorhandensein von Ösophagusvarizen...

4.2 Untersuchung weiterer sonographischer Aspekte als indikative Parameter für das Vorhandensein von Ösophagusvarizen .....................................................................................35

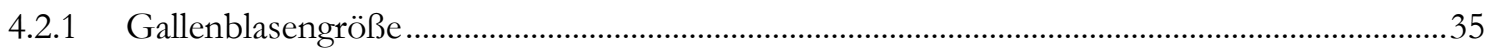

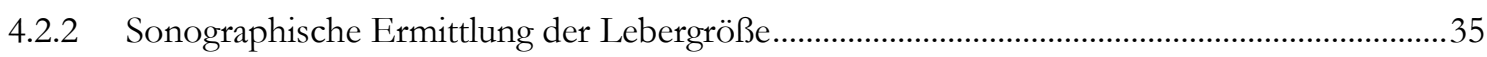

4.2.3 Sonographische Zeichen des Leberparenchymumbaus ..............................................................36

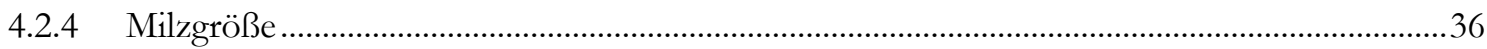

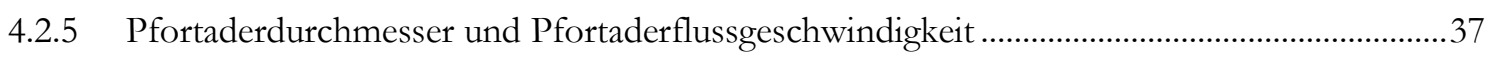

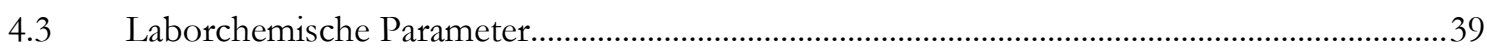

4.4 Steifigkeitsmessungen als Ermittlungsverfahren von Leberstrukturumbau und portaler

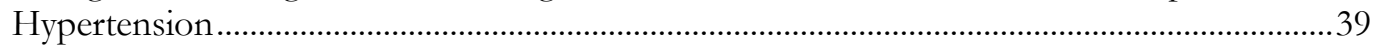

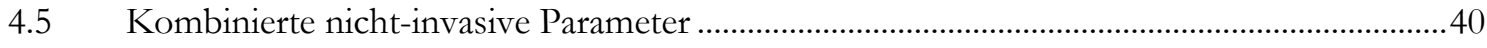

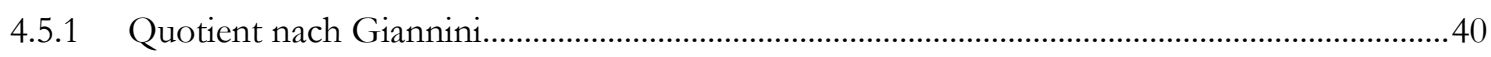

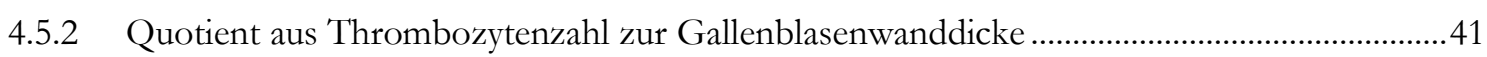

4.5.3 Kombination von Gallenblasenwanddicke, Milzlänge, Thrombozytenzahl und Child-

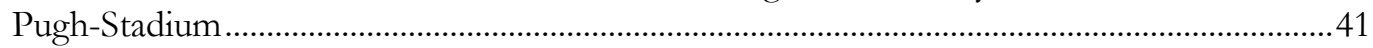

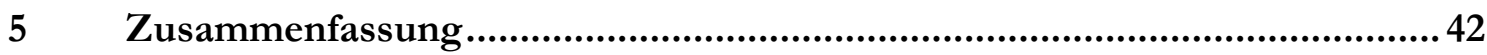

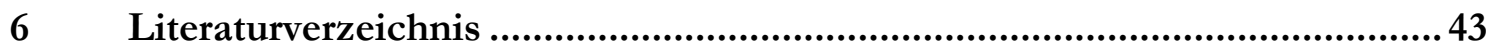




\section{Abbildungsverzeichnis}

Abbildung 2-1: Sonographische Ausmessung der Gallenblasenwanddicke..... 10

Abbildung 2-2: Sonographische Ausmessung der Milzgröße

Abbildung 3-1: Altersverteilung im Vergleich der Untergruppen mit bzw. ohne Ösophagusvarizen.

Abbildung 3-2: Vorhandensein von Ösophagusvarizen abhängig von der Ätiologie

Abbildung 3-3: Boxplot zur Gallenblasenwanddicke in der Gruppe mit und der ohne Ösophagusvarizen.

Abbildung 3-4: Vergleich der Mittelwerte der Gallenblasenwanddicke abhängig vom Schweregrad der Ösophagusvarizenausprägung.

Abbildung 3-5: Auswertung der Milzlänge als Boxplot der Gruppe mit und der ohne Ösophagusvarizen

Abbildung 3-6: Vergleich der Milzlänge abhängig vom Schweregrad der Ösophagusvarizen nach Paquet.

Abbildung 3-7: Vergleich der Thrombozytenzahl als Boxplot zwischen der Gruppe mit und der ohne Ösophagusvarizen.

Abbildung 3-8: Vergleich der Mittelwerte der Thrombozytenzahl abhängig vom Ausprägungsgrad der Ösophagusvarizen nach Paquet.

Abbildung 3-9: Aufteilung der Patienten nach Child-Pugh-Klassifikation mit Angabe des prozentualen Anteils des Ösophagusvarizennachweis

Abbildung 3-10: Einteilung der Patienten nach Child-Pugh-Klassifikation abhängig von der Ausprägung von Ösophagusvarizen .............................................................................2

Abbildung 3-11: Grenzwertoptimierungskurve für den Quotienten nach Giannini 29

Abbildung 3-12: Grenzwertoptimierungskurve für den Quotienten aus Gallenblasenwanddicke in Millimetern zu der Thrombozytenzahl 


\section{Tabellenverzeichnis}

Tabelle 1-1: Fibrosegrad-Einteilung nach Desmet/Scheuer und nach METAVIR ..... 3

Tabelle 1-2: Gradeinteilung von Ösophagusvarizen nach Paquet..........................................................4

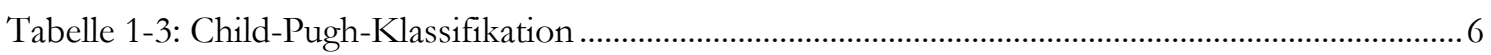

Tabelle 1-4: Überlebenswahrscheinlichkeit abhängig vom Child-Pugh-Stadium................................6

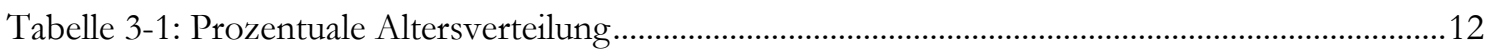

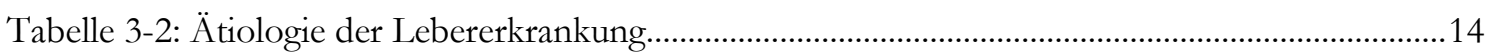

Tabelle 3-3: Verteilung der Patienten ohne bzw. mit Ösophagusvarizen abhängig von der Ätiologie der Lebererkrankung ...........................................................................................15

Tabelle 3-4: Korrelation der Gallenblasenwanddicke mit anderen sonographischen Parametern.....18

Tabelle 3-5: Korrelation der Gallenblasenwanddicke mit laborchemischen Parametern ...................19

Tabelle 3-6: Sonographisch bestimmte Parameter abhängig vom Ösophagusvarizennachweis mit Angabe von Mittelwert und Standardabweichung ...........................................................23

Tabelle 3-7: Laborchemische abhängig vom Ösophagusvarizennachweis mit Angabe von Mittelwert und Standardabweichung

Tabelle 3-8: Unterteilung der Patienten abhängig von der Ösophagusvarizenausprägung sowie

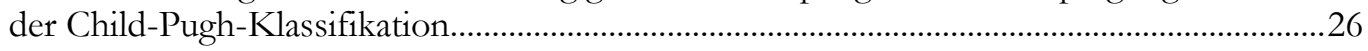

Tabelle 3-9: Ergebnisse der multivariaten Analyse ...........................................................................27

Tabelle 3-10: Vergleich der sonographischen Einzelparameter in Bezug auf die Vorhersagewahrscheinlichkeit von Ösophagusvarizen

Tabelle 3-11: Vergleich von summativen Parametern in Bezug auf die Vorhersagewahrscheinlichkeit von Ösophagusvarizen 


\section{Abkürzungsverzeichnis}

AASLD American Association for the Study of Liver Diseases

AIH

Autoimmunhepatitis

ALT

Alanin-Aminotransferase

ARFI

acoustic radiation force impulse

AST

Aspartat-Aminotransferase

AUC

area under curve

AUROC

area under the receiver operating characteristic

AWMF

Arbeitsgemeinschaft der Wissenschaftlichen Medizinischen Fachgesellschaften e.V.

GGT

Gamma-Glutamyltransferase

HBV

Hepatitis-B-Virus

HCC

hepatocellular carcinoma; hepatozelluläres Karzinom

$\mathrm{HCV}$

Hepatitis-C-Virus

HEV

Hepatitis-E-Virus

HVPR

bepatic venous pressure gradient

INR

international normalized ratio

LSPS

liver stiffness $\times$ spleen diameter / platelet count

MCL

Medioclavicularlinie

MELD

model of end stage liver disease

METAVIR

meta-analysis of histological data in viral hepatitis

mHAI

modified hepatic activity index; modifizierter hepatischer Aktivitätsindex

NAFLD

non-alcoholic fatty liver disease; nicht-alkoholische Fettleber

PBC

primär biliäre Cholangitis

$\mathrm{PH}$

portal hypertension; portale Hypertension

PSC

primär sklerosierende Cholangitis

ROC

receiver operating curve; Grenzwertoptimierungskurve

TIPS

transjugulärer intrahepatischer portosystemischer (Stent-)Shunt

WHO World Health Organization; Weltgesundheitsorganisation 


\section{$1 \quad$ Einleitung}

In den USA sowie in Westeuropa wird eine Prävalenz der Leberzirrhose von 0,15\% bis $0,3 \%$ der Bevölkerung angenommen (Blachier et al. 2013). In Asien wird die Erkrankungsrate auf Grund der weiteren Verbreitung von Hepatitis-B-Infektionen deutlich höher eingeschätzt. Weil eine Leberzirrhose oft lange unerkannt bleibt, da eine klinische Symptomatik häufig erst spät auftritt, liegt Schätzungen zu Folge bei bis zu einem Prozent der Bevölkerung eine Leberzirrhose vor (Tsochatzis et al. 2014). Exakte Daten sind schwer ermittelbar, auch weil eine Unterscheidung zwischen hochgradiger Fibrose und Leberzirrhose histologisch getroffen wird und die Klinik alleine nicht beweisend ist.

Gefürchtete Komplikationen bei bestehender Leberzirrhose sind die Entwicklung einer spontanen bakteriellen Peritonitis, einer hepatischen Enzephalopathie, eines hepatorenalen, hepatokardialen oder hepatopulmonalen Syndroms, aber auch die Entstehung von Ösophagusvarizen oder eines hepatozellulären Karzinoms (HCC). Auf Grund der deutlich erhöhten Gefahr bei Patienten mit Leberzirrhose, ein Malignom zu entwickeln, empfiehlt die Leitlinie der AWMF von Mai 2013 die halbjährliche sonographische Kontrolle der Leber (Plentz et al. 2014; Sommer et al. 2014). Im Rahmen dieser Untersuchung wäre eine Suche nach Hinweisen für das Vorliegen von Ösophagusvarizen sinnvoll, da diese unbehandelt zu massiven und gefürchteten Blutungen führen können. Diese sind bei etwa $50 \%$ aller Patienten mit Leberzirrhose vorhanden (Pagliaro et al. 1992; Garcia-Tsao et al. 2007). Eine durch nicht-invasive Parameter ermittelbare Wahrscheinlichkeit von klinisch relevanter portaler Hypertension könnte zu einer Reduktion der Untersuchungsanzahl an Ösophagogastroskopien führen. Auch ist eine Sonographie in Schwellenländern eher zugänglich als eine endoskopische Untersuchung, so dass eine nicht-invasive Risikostratifizierung zur Indikationsstellung vorteilhaft ist. Die invasive endoskopische Diagnostik ist an sich mit einem Risiko verbunden, wie zum Beispiel Auslösung von Blutungen, insbesondere bei der häufig mit portaler Hypertension assoziierten Thrombozytopenie (Oh et al. 2017). Die häufig erforderliche Sedierung birgt ebenfalls ein Komplikationsrisiko, wobei Studien, die endoskopische Untersuchungen mit und ohne Sedierung vergleichen, rar sind, vor allem, weil derzeitig die meisten Patienten einen starken Wunsch nach Sedierung zur Untersuchung äußern (Riphaus et al. 2015). Bisherige nichtinvasive Indikatoren für das Vorliegen von Ösophagusvarizen konnten sich als Screeningparameter nicht durchsetzen. Auf Grund der besonderen Blutversorgung der Gallenblasenwand mit venösen Abfluss im Wesentlichen in die Pfortader (Johnston und Anson 1952) kann ein Rückstau mit konsekutiver Gallenblasenwandverdickung bei klinisch relevanter portaler Hypertension angenommen werden. Die Assoziation einer verdickten Gallenblasenwand mit dem endoskopischen Nachweis von Ösophagusvarizen wurde bisher bei Erwachsenen nicht untersucht. Ziel dieser Arbeit ist daher die Untersuchung der 
Gallenblasenwanddicke als nicht-invasiver Parameter für das Vorliegen von Ösophagusvarizen.

\subsection{Leberfibrose und Leberzirrhose}

Die Ätiologie der Leberzirrhose ist mannigfaltig: in Westeuropa häufigste Ursachen sind die äthyltoxische Genese und virale Hepatitiden, zunehmend an Bedeutung gewinnt außerdem die nicht-alkoholische Steatohepatitis (Fleming et al. 2012). Laut WHO-Bericht von Juli 2017 sind geschätzte 257 Millionen Menschen weltweit mit dem Hepatitis-B-Virus infiziert. Dabei sind besonders die Westpazifik-Region sowie Afrika mit 6,2\% bzw. 6,1\% der Bevölkerung betroffen (WHO (2018a): Hepatitis-B fact sheet). Der Hepatitis-C-Virus hat laut WHOSchätzungen, ebenfalls vom Juli 2017, circa 71 Millionen Menschen infiziert. Die höchste Prävalenz liegt im Osten des Mediterraneums mit 2,3\%, gefolgt von europäischen Ländern mit 1,5\% (WHO (2018b): Hepatitis C fact sheet). In Deutschland ist in 50-60\% der Fälle von einer äthyltoxischen Genese auszugehen (Schepke et al. 2004) (Sauerbruch et al. 1988), was zu einer höheren Sterblichkeit als andere Ursachen der Leberzirrhose führt (Fleming et al. 2012). Außerdem spielen autoimmune Prozesse wie die Autoimmunhepatitis, die primär biliäre Cholangitis (PBC) sowie die primär sklerosierende Cholangitis (PSC) eine Rolle. Genetische Faktoren wie die Hämochromatose oder Morbus Wilson sind ebenfalls zu erwähnen. Bei den meisten dieser Erkrankungen schreitet die Krankheit langsam über Jahre bis Jahrzehnte voran. Es kommt zu einer zunehmenden Fibrosierung durch vermehrte Bildung von Extrazellulärmatrix mit veränderter Zusammensetzung. Ist eine weitere Umbildung eingetreten, hin $\mathrm{zu}$ einer zirrhotischen Leber, so besteht das gebildete Narbengewebe vorwiegend aus fibrillenformenden Kollagenen und Matrixglykokonjugaten (Baiocchini et al. 2016). Entgegen früher vorherrschender Überzeugung ist weder die Fibrose noch die Zirrhose ein unumkehrbarer Prozess, sofern die auslösende Ursache therapiert wird (Shiratori et al. 2000; Hammel et al. 2001). Allerdings konnte auch gezeigt werden, dass auch nach Elimination einer Hepatitis-Virus-Infektion eine klinische Verschlechterung der Lebererkrankung sowie die Entwicklung eines hepatozellulärem Karzinoms möglich ist, so dass diese Patienten weiter überwacht werden sollten (Cordero-Ruiz et al. 2017). Die Wahrscheinlichkeit einer Rückbildung der pathologischen Leberveränderungen sinkt von fibrotischer zur zirrhotischen Leber hin deutlich ab. Die histologische Einteilung erfolgt üblicherweise nach Desmet und Scheuer (Desmet et al. 1994) sowie nach METAVIR (Bedossa und Poynard 1996). 
Tabelle 1-1: Fibrosegrad-Einteilung nach Desmet/Scheuer und nach METAVIR

\begin{tabular}{|l|l|l|}
\hline $\begin{array}{l}\text { Fibrose- } \\
\text { stadium }\end{array}$ & Desmet Scheuer & METAVIR \\
\hline F0 & keine Fibrose & keine Fibrose \\
\hline F1 & portale Fibrose & portale Fibrose \\
\hline F2 & periportale Fibrose +/- Septen portoportal & portale Fibrose mit wenigen Septen \\
\hline F3 & - & portale Fibrose mit vielen Septen \\
\hline F3/F4 & $\begin{array}{l}\text { septenbildende Fibrose mit gestörter } \\
\text { Architektur (keine Zirrhose) }\end{array}$ & - \\
\hline F4 & Zirrhose & Zirrhose \\
\hline
\end{tabular}

Klinisch kann sich die Leberzirrhose unter anderem mit eingeschränkter Syntheseleistung, hepatischer Enzephalopathie sowie den Folgen der portalen Hypertension präsentieren, die Ösophagusvarizen und auch Aszites verursacht. Zur klinischen Einteilung ist eine Einstufung nach Child-Pugh-Turcotte geläufig (Pugh et al. 1973; Infante-Rivard et al. 1987). Der MELD-Score wird bezüglich der Mortalitätsvorhersage zur Zeit noch diskutiert, so ist die Anwendung des Child-Pugh-Score mit zusätzlicher Einbeziehung des Kreatininwertes zur Berechnung der 3- und 12-Monats-Mortalität dem MELD-Score nicht unterlegen (Kalafateli et al. 2017).

\subsection{Portale Hypertension}

Die Ätiologie der portalen Hypertension hat weltweit unterschiedliche Genesen. Während in Europa und Nordamerika eine Leberschädigung auf sinusoidaler Ebene in $90 \%$ ursächlich ist, so verursacht in Afrika, Asien und Südamerika die Schistosomiasis häufig eine portale Hypertension. Auch kommt eine idiopathische Genese in Japan und Indien gehäuft vor (Bosch et al. 1989). Bei bestehender Leberzirrhose kommt es sowohl durch einen Anstieg des intrahepatischen vaskulären Widerstandes als auch durch einen zunehmenden Blutfluss der Pfortaderkollateralen zum portalen Hypertonus (Groszmann und Abraldes 2005). Dieser ist definiert als ein erhöhter Gradient zwischen Pfortader und Lebervenen. Der Gradient beträgt bei einem gesunden Individuum maximal $5 \mathrm{mmHg}$. Ab einer Differenz von 10 mmHg und mehr spricht man von relevantem portalem Hypertonus (Mitra 1966). Bei den wenigsten Patienten wird allerdings der portale Hypertonus mittels Angiographie und Messung des hepatischen venösen Druckes in der rechten Lebervene sowie des WedgeDruckes an selber Position bestätigt. Da diese invasive Diagnostik nicht ohne Risiken ist, wird in der Regel anhand der klinischen Präsentation des Patienten ein portaler Hypertonus angenommen (Berzigotti et al. 2013). Sonographische und laborchemische Parameter können ergänzende Hinweise liefern. Weitere nicht-invasive Methoden zur Abschätzung sowohl von fortgeschrittener Leberzirrhose als auch von portaler Hypertension mittels Lebersteifigkeitsmessung sind bisher nicht als Alternativen ausreichend etabliert, als hinweisend können sie hilfreich sein. Eine Erhöhung der Sensitivität zur Abschätzung der 
portalen Hypertension mittels weiterer sonographischer Surrogatparameter ist daher von Interesse.

\subsection{Problematik der Ösophagusvarizen}

Bereits bei Erstdiagnose einer Leberzirrhose werden bei $40 \%$ der Patienten Ösophagusvarizen beschrieben (Groszmann et al. 2005). Nach einem Jahr ist eine Progression bei 12\% der Patienten, nach drei Jahren bei 31\% beschrieben (Merli et al. 2003). Das Risiko steigt im Laufe von 10 Jahren auf $90 \%$ an. Auch nimmt die Blutungswahrscheinlichkeit aus Ösophagusvarizen von 7 auf 40\% im 10-Jahresintervall zu (Christensen et al. 1981). Bei bereits statt gehabter Ösophagusvarizenblutung beträgt die Wahrscheinlichkeit eine erneute Varizenblutung zu erleiden etwa 70\% (Burroughs 1993), ältere Quellen geben sogar 81\% an, was an den veränderten Therapiemöglichkeiten liegen kann (Christensen et al. 1981). Nach erlittener Varizenblutung lag 1993 die Mortalitätsrate im sechswöchigen Intervall bei $50 \%$ (Burroughs 1993). Aktuell wird im selben Nachbeobachtungsintervall eine Mortalität von maximal 37\% angegeben (de Franchis und Primignani 2001; Hsieh et al. 2017). Ösophagusvarizen und die Entwicklung von Aszites sind bei Nachweis einer Leberzirrhose wesentlich mit der Mortalität assoziiert, so versterben nur 5\% der Betroffenen ohne Aszitesbildung oder statt gehabter Varizenblutung (D'Amico und Luca 1997). Zusätzlich oder unabhängig von Ösophagusvarizen können auch Kardiaoder Fundusvarizen auftreten, die in ihrer Prävalenz deutlich weniger häufig als Ösophagusvarizen auftreten (Sarin et al. 1992).

Eine Einteilung der Ösophagusvarizen erfolgt aktuell üblicherweise nach der Klassifikation nach Paquet, die wie folgt lautet (Paquet 1982):

Tabelle 1-2: Gradeinteilung von Ösophagusvarizen nach Paquet

\begin{tabular}{|l|l|}
\hline Grad & Endoskopischer Befund \\
\hline I & Varizen überragen das Schleimhautniveau \\
\hline II & $\begin{array}{l}\text { Varizen } \leq 1 / 3 \text { des Ösophaguslumens, sind durch Luftinsufflation nicht mehr } \\
\text { komprimierbar }\end{array}$ \\
\hline III & Varizen $\leq 1 / 2$ des Ösophaguslumens und berühren sich teils gegenseitig \\
\hline IV & Varizen füllen das Ösophaguslumen aus und ragen bis ins obere Ösophagusdrittel \\
\hline
\end{tabular}

Zusätzlich wird das Vorhandensein von red spots oder red wale marks sowie das Child-PughStadium in die Risikostratifizierung einbezogen (NIECSTEV 1988). Bei niedriger Blutungswahrscheinlichkeit wird eine Primärprophylaxe mit einem nicht-selektiven Betablocker wie Propranolol empfohlen, sofern eine auseichende Dosis zur Senkung des hepatovenösen Druckgradienten toleriert wird (D'Amico et al. 1999; Merkel et al. 2004). Eine Varizenligatur wird ab Ösophagusvarizen zweiten Grades mit zusätzlichen red wale marks oder ab drittgradigen Ösophagusvarizen empfohlen. Die Leitlinie der American Association for the Study of Liver Diseases (-kurz AASLD-) empfiehlt zusätzlich zur Gastoskopie bei 
Erstdiagnose einer Leberirrhose eine Wiederholungsendoskopie bei Child-Pugh-A-Stadium nach 2 Jahren, bei Child-Pugh-B- und -C-Stadium bereits nach einem Jahr (Garcia-Tsao et al. 2007). Burroughs empfiehlt, die Intervalldauer abhängig von dem Befund bei der letzten Gastroskopie zu machen. So sollte bei Fehlen von Varizen ein Kontrollintervall von zwei Jahren, bei Nachweis von Varizen jeden Grades jährliche Kontrollen gewählt werden (Burroughs 1993). Das Blutungsrisiko einer diagnostischen Gastroskopie beträgt 1,3 Fälle pro 1000 Untersuchungen. Eine endoskopische Varizenligatur gehört zu den endoskopischen Prozeduren mit erhöhtem Blutungsrisiko (Silvis et al. 1976).

\subsection{Laborchemische Aspekte in Assoziation mit Ösophagusvarizen}

Eine Unterscheidung zwischen laborchemischen Parametern, die auf eine Leberzirrhose oder die speziell auf eine portale Hypertension hinweisen, ist nicht eindeutig möglich. Laborwerte, die eine verminderte Lebersyntheseleistung aufweisen, sind die Prothrombinzeit, auch Quick genannt, sowie der International Normalized Ratio (INR), aber auch Protein und insbesondere Albumin im Serum. Die Ausscheidung von konjugiertem Bilirubin durch die Hepatozyten ist bei Leberzellschädigung eingeschränkt, was zu einer Erhöhung des konjugierten Bilirubins im Serum führt. Auch eine Erhöhung der Transaminasen kann auf eine Leberzellschädigung deuten, sofern ein Hinweis auf eine andere Organschädigung fehlt. Dabei ist der Quotient aus Aspartat-Aminotransferase (AST) und Alanin-Aminotransferase (ALT) etabliert zur weiteren Unterscheidung der Genese der Leberschädigung. So wird ein Wert kleiner oder gleich eins üblicherweise bei einer akuten oder einer chronischen Lebererkrankung ohne wesentlichen fibrotischen Umbau gesehen. Bei Patienten mit Zirrhose liegt der gebildete Quotient eher bei größer als eins. Eine Erhöhung auf über zwei des gebildeten Quotienten in Zusammenschau mit einer Erhöhung der Gamma-Glutamyltransferase (GGT) ist eine typische Konstellation bei äthyltoxischer Genese (Agrawal et al. 2016). Die GGT ist assoziiert mit einem fibrotischem Umbau bei nicht-alkoholischer Steatosis hepatis, auch non-alcoholic fatty liver disease (NAFLD) genannt (Tahan et al. 2008).

Eine Einschätzung der Prognose bei Leberzirrhose erfolgt häufig über den Child-TurcottePugh-Score. Bei diesem werden sowohl Prothrombinzeit, Albumin als auch Bilirubin zusammen mit den klinischen Aspekten der hepatischen Enzephalopathie und dem Aszites berücksichtigt. Abhängig von einer vorgeschriebenen Punktevergabe kann so eine Einteilung in drei Gruppen erfolgen. Dabei entspricht ein Punktwert von fünf oder sechs Child-PughStadium A, sieben bis neun Punkte entsprechen Stadium B und zehn bis fünfzehn Punkte Stadium C (Pugh et al. 1973). 
Tabelle 1-3: Child-Pugh-Klassifikation

\begin{tabular}{|l|l|l|l|l|}
\hline Kriterium & 1 Punkt & 2 Punkte & 3 Punkte & Einheit \\
\hline Serum-Bilirubin (gesamt) & $<2,0$ & $2,0-3,0$ & $>3,0$ & $\mathrm{mg} / \mathrm{dl}$ \\
\hline Serum-Albumin & $>3,5$ & $2,8-3,5$ & $<2,8$ & $\mathrm{~g} / \mathrm{dl}$ \\
\hline Quick-Wert & $>70$ & $40-70$ & $<40$ & $\%$ \\
\hline Aszites im Ultraschall & keiner & Leicht & mittelgradig & - \\
\hline hepatische Enzephalopathie & keine & Stadium I-II & Stadium III-IV & - \\
\hline
\end{tabular}

Patienten im Child-Pugh-Stadium $\mathrm{C}$ haben eine signifikant schlechtere Prognose als Patienten im Stadium B, die wiederum eine signifikant schlechtere Prognose als Patienten des Child-Pugh-Stadiums A haben (Pugh et al. 1973). In einer Auswertung von 118 Studien zur Mortalität abhängig vom Child-Pugh-Score zeigte sich die mittlere 1- und 2Jahresüberlebenswahrscheinlichkeit wie folgt (D'Amico et al. 2006):

Tabelle 1-4: Überlebenswahrscheinlichkeit abhängig vom Child-Pugh-Stadium

\begin{tabular}{|l|l|l|}
\hline Child-Pugh-Stadium & 1-JÜR & 2-JÜR \\
\hline A & $95 \%$ & $90 \%$ \\
\hline B & $80 \%$ & $70 \%$ \\
\hline C & $45 \%$ & $38 \%$ \\
\hline
\end{tabular}

Die Prognose ist jedoch in jedem Stadium auch abhängig von der Ursache der Leberschädigung. Bei Patienten mit dekompensierter Leberzirrhose und PBC als Grunderkrankung ist die Prognose besser als bei anderen Genesen. Patienten mit dekompensierter Leberzirrhose äthyltoxischer Genese haben die schlechteste Prognose (Propst et al. 1995).

Der Child-Turcotte-Pugh-Score weist auf die Wahrscheinlichkeit von Ösophagusvarizenblutungen hin. So ist bei der Auswertung von 126 Patienten mit Leberzirrhose und Ösophagusvarizen der Anteil an Patienten im Stadium Child-Pugh-C 46,9\%, Child-Pugh-B 37,5\% und an denen im Stadium A 15,6\% (Radisavljević et al. 2017).

Bei Patienten, die für eine Lebertransplantation gelistet sind, wird der MELD-Score verwendet, der in der Abschätzung der Mortalität im Drei-Monats-Intervall statistisch bewiesen genauer ist als der Child-Turcotte-Pugh-Score (Wiesner et al. 2003). Der MELDScore wurde ursprünglich zur Berechnung der Mortalität bei elektiver transjugulärer portosystemischer Shuntanlage (TIPS) geschaffen. Er wird bezüglich der Mortalitätsvorhersage zur Zeit noch diskutiert, so ist die Anwendung vom Child-Pugh-Score mit zusätzlicher Einbeziehung des Kreatininwertes zur Berechnung der 3- und 12-MonatsMortalität dem MELD-Score nicht unterlegen (Kalafateli et al. 2017).

Die Berechnung des MELD-Scores ergibt sich aus den laborchemischen Parametern INR, Kreatinin und Bilirubin wie folgt (Malinchoc et al. 2000): 
$10 \mathrm{x}(0.957 \mathrm{x} \ln ($ Serumkreatinin $[\mathrm{mg} / \mathrm{dl}])+0.378 \times \ln ($ Bilirubin ges. $[\mathrm{mg} / \mathrm{dl}])+1.12 \mathrm{x} \ln (\mathrm{INR})$ $+0.643)$.

Der MELD-Score ist ein unzuverlässiger Parameter in Bezug auf die Blutungswahrscheinlichkeit von Ösophagusvarizen (Chakrabarti et al. 2016).

Als Folge der portalen Hypertension kommt es in der Regel zur Splenomegalie. Durch einen Hypersplenismus kann es wiederum zu einer Thrombozytopenie durch eine vermehrte Sequestration der Zellen in der Milz kommen. Der Plättchenmangel kann aber auch durch die verminderte Synthese von Thrombopoetin bei Leberzirrhose mitbedingt sein (Giannini et al. 2003b). Eine direkte Knochenmarksschädigung durch toxische Substanzen, die zugleich die Leberschädigung verursachen, ist ebenfalls als Genese der verminderten Anzahl der Blutplättchen möglich (Shi et al. 2017).

\subsection{Sonographische Aspekte in Assoziation mit Ösophagusvarizen}

Bei Lebererkrankungen sollte insbesondere die Leber genau sonographisch untersucht und beschrieben werden. Dazu gehören sowohl die Lebergröße, das Erscheinungsbild der Leber hinsichtlich Kontur, Form, Oberfläche und Parenchym als auch Auffälligkeiten der Lebergefäße. Ein gehäuftes Auftreten von Pfortaderthrombosen im Rahmen einer fortgeschrittenen Lebererkrankung ist pathophysiologisch mit einem erhöhtem portalen Hypertonus assoziiert. Aus diesem Grund wird auch eine Verlangsamung der Flussgeschwindigkeit der Pfortader eher in Verbindung mit dem Auftreten von Ösophagusvarizen angesehen. Eine Folgeerscheinung der Lebererkankung mit Erhöhung des hepatovenösen Druckgradienten ist eine Hypertrophie der Milz, so dass die Milzgröße als Hinweis auf die Wahrscheinlichkeit von Umgehungskreisläufen vermessen werden sollte. Zeichen der Dekompensation einer Leberzirrhose in Form von Aszites sollten ebenfalls dokumentiert werden.

Bei der sonographischen Untersuchung von Patienten mit Lebererkrankungen ist eine verdickte Gallenblasenwand auch bei fehlendem Hinweis auf eine Cholezystitis nicht selten zu beschreiben. Es wird vermutet, dass das Vorliegen von Aszites eine physikalisch bedingte Unschärfe der Gallenblasendarstellung verursacht. Ebenso wird eine Hypalbuminämie als mit ursächlich angenommen (Colli et al. 1991a). Bedenkt man jedoch die besondere Blutversorgung der Gallenblase, so erscheinen pathophysiologische Veränderungen relevanter für dieses Phänomen. Arteriell wird die Gallenblase durch die A. cystica, die in der Regel aus der A. hepatica dextra abgeht, versorgt. Der venöse Abfluss erfolgt bei 60\% über die V. cystica in den rechten Hauptast der Pfortader sowie über den Plexus venosus ductus hepatici et choledochi und kleine Venen des Gallenblasenbettes direkt in das Lebersegment fünf (Johnston und Anson 1952). Auf Grund des vorwiegenden Abflusses in die Pfortader ist ein Rückstau bei klinisch relevantem portalen Hypertonus wahrscheinlich, der dann wiederum die Gallenblasenwand ödematös auftreibt (Li et al. 2010). Ein Zusammenhang zwischen einer verdickten Gallenblasenwand und bestehenden Ösophagusvarizen ist bisher 
nicht bei Erwachsenen beschrieben. Die Untersuchung der sonographisch ermittelten Gallenblasenwanddicke als nicht-invasiver Marker für das Vorliegen von Ösophagusvarizen erfolgt erstmalig im nicht-pädiatrischen Bereich. Wegen des beschriebenen vermuteten pathophysiologischen Zusammenhangs zwischen einer nicht entzündlich bedingten Gallenblasenwandverdickung und dem Auftreten von Ösophagusvarizen bietet die sonographische Ausmessung der Wanddicke Potential als neuer nicht-invasiver Parameter für das Vorhandensein von Varizen.

\subsection{Fragestellung}

In dieser Studie wurden Daten von 194 Patienten mit einer Erkrankung der Leber analysiert, um nicht-invasive Prädiktoren zu untersuchen, die auf das Vorhandensein von Ösophagusvarizen mit hoher Wahrscheinlichkeit hinweisen. Dabei wurde erstmalig bei Erwachsenen die Gallenblasenwanddicke als neuer nicht-invasiver Parameter betrachtet. Ziel dieser Studie ist es, die Gallenblasenwanddicke sowohl in ihrer Aussagekraft als Einzelparameter als auch in Kombination mit anderen nicht-invasiv ermittelten Werten im Hinblick auf das Vorliegen von Ösophagusvarizen zum ersten Mal zu untersuchen. 


\section{$2 \quad$ Material und Methoden}

\subsection{Patientenkollektiv}

Von den 6600 Untersuchungen, die zwischen April 2015 und Januar 2016 in der Abteilung für Gastroenterologie und gastrointestinale Onkologie sonographisch untersucht wurden, bestand bei 507 Patienten eine Hepatopathie. Es erfolgte eine standardisierte Erfassung von sonographischen Daten sowie klinischen, laborchemischen und endoskopischen Daten wie im Weiteren beschrieben. Anschließend wurden die Patienten, bei denen eine Gastroskopie durchgeführt worden war, herausgefiltert und für diese Studie verwendet. Dabei erfolgte ein Vergleich zwischen Patienten mit Ösophagusvarizen und denen ohne Beschreibung von Ösophagusvarizen in Bezug auf Gallenblasenwanddicke, Milzgröße, Child-Pugh-Stadium, Aszites und Thrombozytenzahl unter anderem.

\subsection{Datenerfassung}

\subsubsection{Sonographie}

Die sonographische Untersuchung wurde von Ärzten der Abteilung Gastroenterologie und gastrointestinale Onkologie oder aus der Abteilung für Hämatologie und Onkologie durchgeführt, die erfahren in der standardisierten Untersuchung sind. Es wurde bei jedem Patienten zunächst die Lebergröße in der Medioclavicularlinie in mittlerer Inspirationstiefe ausgemessen. Eine Ausmessung der Gallenblase erfolgte mit zweimaliger Ermittlung der Gallenblasenwanddicke an unterschiedlichen Messungsorten, von denen der Mittelwert bestimmt wurde wie in Abbildung 2-1 dargestellt. Der Durchmesser der Pfortader wurde am Leberhilus ermittelt, sowie zusätzlich die Pfortaderflußgeschwindigkeit bzw. ein Ausschluss oder eine Dokumentation einer Pfortaderthrombose. Falls im Bereich der Leberpforte Lymphknoten beschrieben wurden, so wurde auch dieses dokumentiert. Das Vorhandensein einer Steatosis hepatis sowie deren sonographische Ausprägung wurden aufgezeichnet und in leichte, mäßige und schwere Steatosis unterteilt, abhängig von der Echogenität, der Schallabschwächung sowie assoziierter Leberveränderungen wie abgerundeter Leberunterrand oder Hepatomegalie. Bei jeder Untersuchung wurde das Vorhandensein bzw. das Fehlen von Zeichen eines Leberparenchymumbaus notiert. Ausschlaggebend hierfür waren folgende Befunde: abgerundeter Leberunterrand in Kombination mit weiteren Veränderungen, inhomogenes Leberparenchym, unregelmäßige Oberfläche, hypertrophierter Lobus caudatus, rarefizierte Lebervenen. Bei jedem Patienten wurde die maximale Milzlänge in Darstellung von der Flanke interkostal dargestellt und vermessen wie in Abbildung 2-2 ersichtlich. Der Ausschluss von Aszites wurde mittels Aufsuchung der 
Prädilektionsstellen (Morison-Pouch, Koller-Pouch, Douglas-Raum, interenterisch) vorgenommen. Bei Vorliegen von Aszites wurde eine grobe Einteilung in geringen Aszitessaum bis mäßig Aszites oder reichlich Aszites durch die Untersucher vorgenommen.

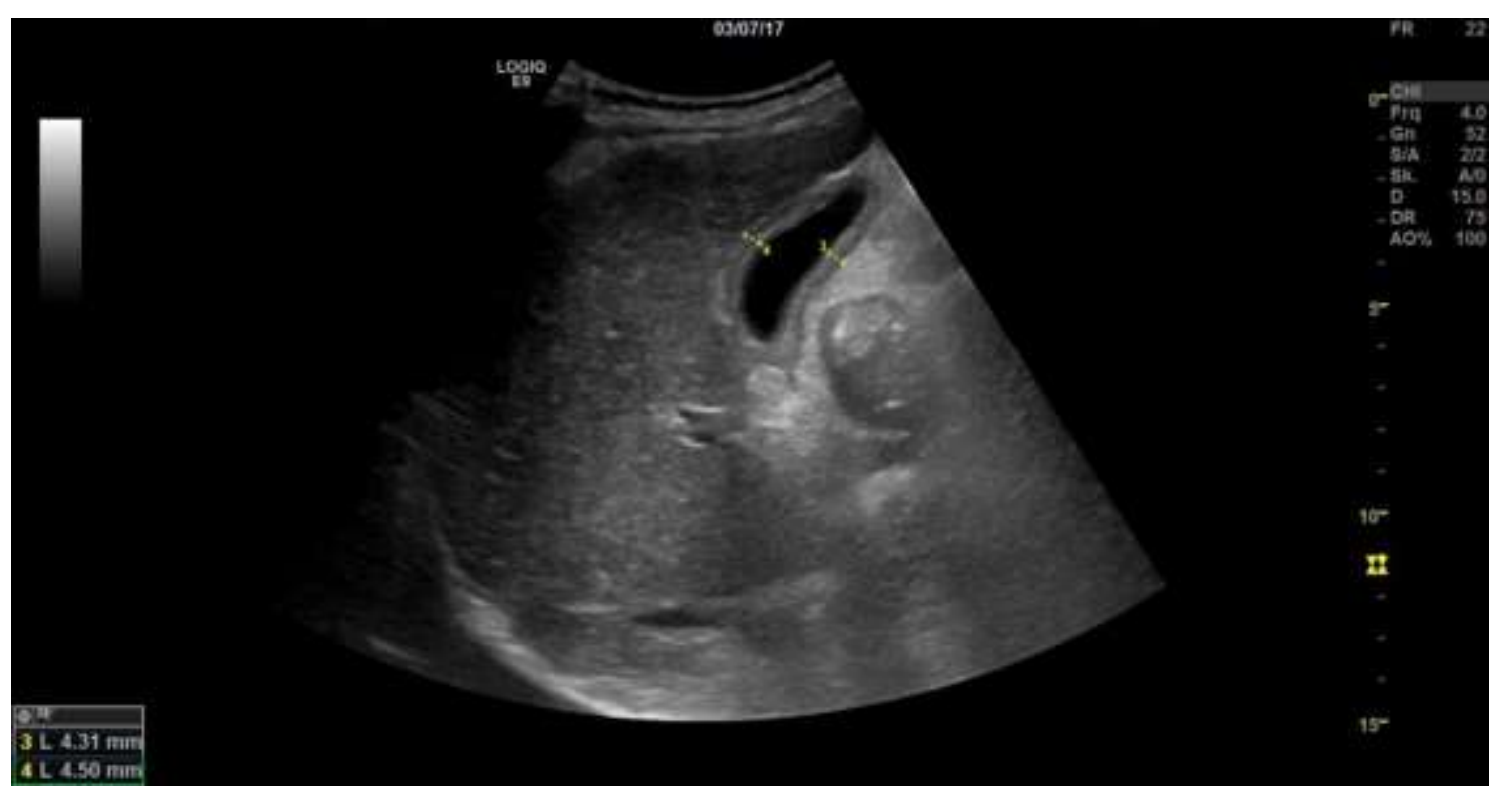

Abbildung 2-1: Sonographische Ausmessung der Gallenblasenwanddicke

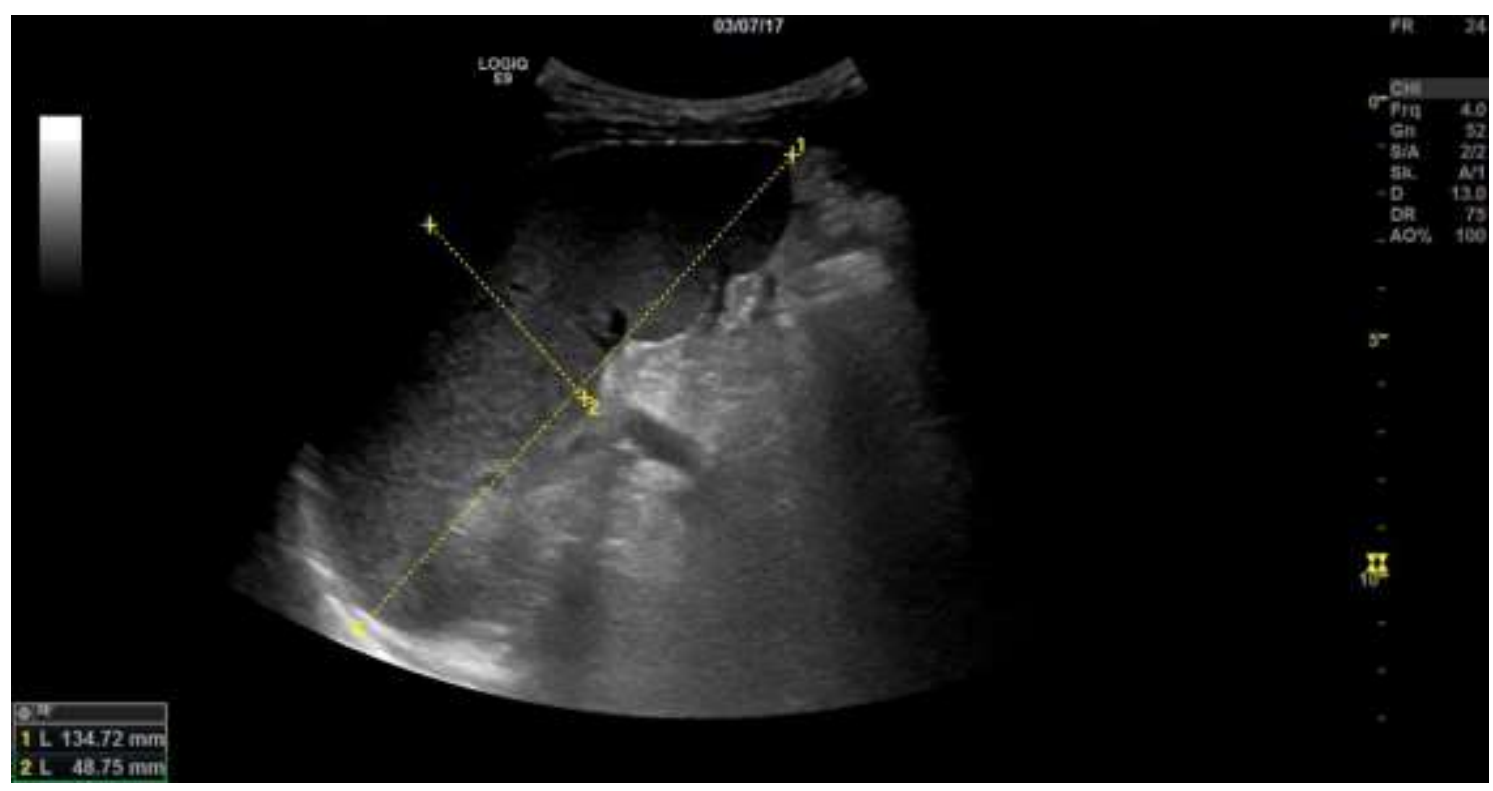

Abbildung 2-2: Sonographische Ausmessung der Milzgröße

\subsubsection{Laborchemie}

Von den in die Studie eigeschlossenen Patienten wurden folgende Parameter erfasst: INR, Thrombozyten, Kreatinin. Die laborchemischen Parameter Quick, Bilirubin und Albumin gingen in die Bestimmung des Child-Pugh-Stadiums mit ein. 


\subsubsection{Endoskopische Beschreibung}

Bei den Patienten wurde das Vorhandensein einer dokumentierten Gastroskopie vor oder nach erfolgter sonographischer Untersuchung innerhalb des Erfassungszeitraumes ermittelt. Dabei wurde zum einen die Beschreibung einer hypertensiven Gastropathie aufgenommen und zum anderen das Vorliegen und die Ausprägung von Ösophagusvarizen. Die Beschreibung der Ösophagusvarizen erfolgte nach der Klassifikation von Paquet (Paquet 1982).

\subsection{Auswertung der Daten}

Alle Angaben wurden in einer Excel-Tabelle erhoben und mit dieser statistisch ausgewertet. Die Auswertung des Signifikanzniveaus erfolgte mittels Anwendung des Student's t-Tests mit Ermittlung des p-Wertes für zweiseitige Testung von zwei heterogenen unverbundenen Stichproben. In der weiteren Auswertung wurde SPSS zur Signifikanzermittlung nach dem Whitney-U-Test angewandt und zur multivariaten Analyse ebenfalls verwendet. 


\section{Ergebnisse}

\subsection{Kollektivzusammensetzung}

\subsubsection{Geschlechterverteilung}

Von den 194 Patienten, deren Daten für die Studie verwendet werden konnten, waren insgesamt 56,7\% männlich und 43,3\% weiblich. Von diesen wurden mittels Gastroskopie bei 72 Patienten Ösophagusvarizen beschrieben. Bei getrennter Betrachtung lediglich der Patienten mit Ösophagusvarizen stieg der Anteil der männlichen Patienten auf 73,6\%.

\subsubsection{Altersverteilung}

Die Altersverteilung zeigte einen Gipfel im Gesamtkollektiv in der Dekade zwischen 61 und 70 Jahren mit kaum weniger Patienten in den beiden vorherigen Altersdekaden (Tabelle 3-1 und Abbildung 3-1).

Tabelle 3-1: Prozentuale Altersverteilung

\begin{tabular}{|l|l|l|l|}
\hline Alter & $\begin{array}{l}\text { Patienten ohne } \\
\text { Ösophagusvarizen }\end{array}$ & $\begin{array}{l}\text { Patienten mit } \\
\text { Ösophagusvarizen }\end{array}$ & Gesamtkollektiv \\
\hline $0-20$ & $1,6 \%$ & $1,4 \%$ & $1,5 \%$ \\
\hline $21-30$ & $3,3 \%$ & $4,2 \%$ & $3,6 \%$ \\
\hline $31-40$ & $1,6 \%$ & $5,6 \%$ & $3,1 \%$ \\
\hline $41-50$ & $25,4 \%$ & $22,2 \%$ & $24,2 \%$ \\
\hline $51-60$ & $27,0 \%$ & $20,8 \%$ & $24,7 \%$ \\
\hline $61-70$ & $22,1 \%$ & $30,6 \%$ & $25,3 \%$ \\
\hline $71-80$ & $16,4 \%$ & $15,3 \%$ & $16,0 \%$ \\
\hline$\geq 81$ & $2,5 \%$ & $0,0 \%$ & $1,5 \%$ \\
\hline
\end{tabular}




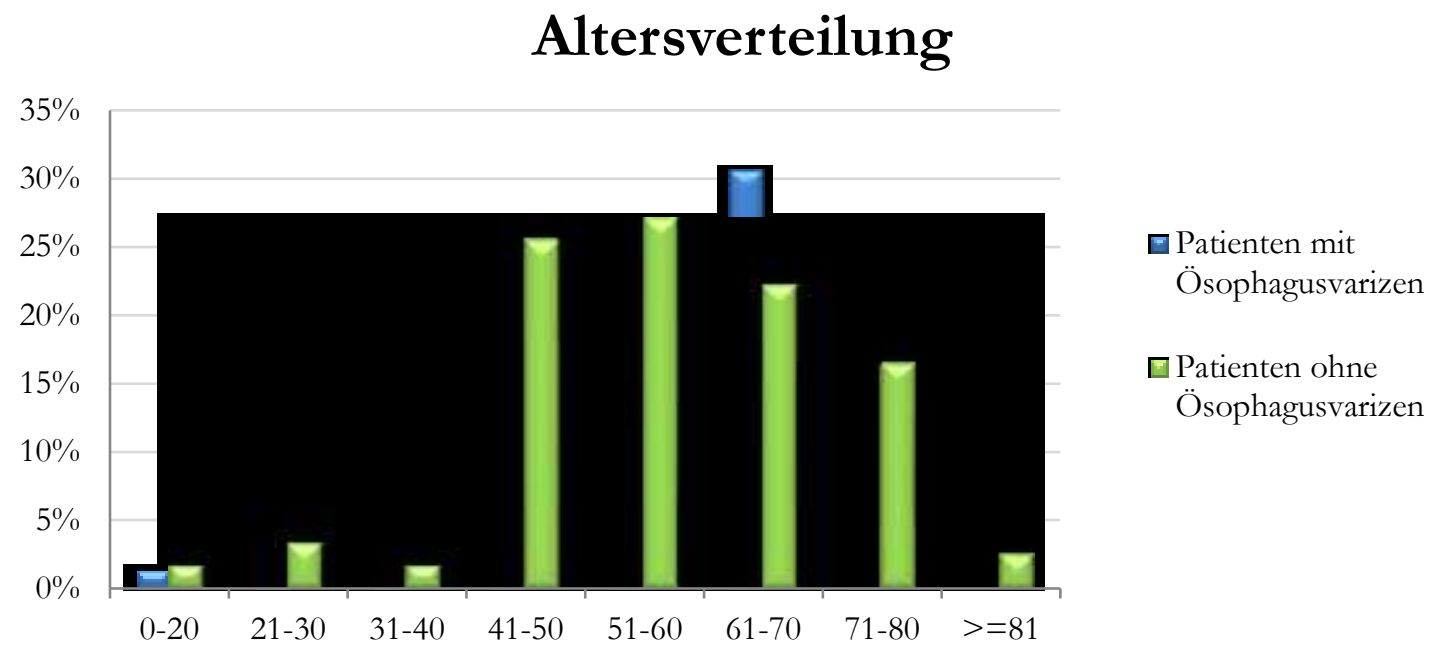

Abbildung 3-1: Altersverteilung im Vergleich der Untergruppen mit bzw. ohne Ösophagusvarizen

\subsection{3 Ätiologie der Lebererkrankung}

Bei Betrachtung der Genese der Lebererkrankung macht eine äthyltoxische Ursache mit 26,3\% im Gesamtkollektiv den größten Anteil aus. Diese Genese ergibt bei den Patienten mit Ösophagusvarizen 45,8\%. Zweithäufigste Krankheitsursache in der gesamten Gruppe macht mit 19,6\% eine noch unklare Hepatopathie oder eine kryptogene Leberzirrhose aus, welche in der Untergruppe ohne Ösophagusvarizen einen etwas größeren Anteil von 22,1\% ergibt. Bei einigen Patienten wurde lediglich der Begriff Leberzirrhose als Angabe zum Grund der Indikation zur Sonographie vermerkt. Ob bei diesen Patienten eine äthyltoxische, virale oder kryptogene Leberzirrhose vorliegt, wurde nicht erfasst, so dass diese Patienten gesondert gelistet sind. Nachfolgend ergeben die Patienten mit Hepatitis B oder C sowie mit ausgeheilter viraler Infektion die nächstgrößere Gruppe mit 19,1\% insgesamt. Weitere Genesen der Lebererkrankungen sind absteigend die folgenden: PBC, Autoimmunhepatitis oder laborchemischer Verdacht auf Vorliegen einer Autoimmunhepatitis, Fettleber, PSC und ischämische Cholangiopathie. Außerdem wurden zu einem geringen Anteil Patienten mit Hepatitis E, Budd-Chiari-Syndrom, Caroli-Syndrom, nachgewiesen medikamentös-toxischer Genese, stattgehabter Pfortaderthrobose, Stauungsleber sowie Hämochromatose erfasst. 
Tabelle 3-2: Ätiologie der Lebererkrankung

\begin{tabular}{|l|l|l|l|}
\hline Ätiologie & $\begin{array}{l}\text { ohne } \\
\text { Ösophagusvarizen }\end{array}$ & $\begin{array}{l}\text { mit } \\
\text { Ösophagusvarizen }\end{array}$ & Gesamtkollektiv \\
\hline Äthyltoxisch & $14,8 \%$ & $45,8 \%$ & $26,3 \%$ \\
\hline (Z.n.) HCV & $12,3 \%$ & $12,5 \%$ & $12,4 \%$ \\
\hline $\begin{array}{l}\text { Kryptogene } \\
\text { Leberzirrhose }\end{array}$ & $3,3 \%$ & $11,1 \%$ & $6,2 \%$ \\
\hline Leberzirrhose & $2,5 \%$ & $9,7 \%$ & $5,2 \%$ \\
\hline (V.a.) AIH & $9,0 \%$ & $6,9 \%$ & $8,3 \%$ \\
\hline unklare Hepatopathie & $18,9 \%$ & $4,2 \%$ & $13,4 \%$ \\
\hline (Z.n.) HBV & $7,4 \%$ & $2,8 \%$ & $5,7 \%$ \\
\hline PSC & $2,5 \%$ & $2,8 \%$ & $2,6 \%$ \\
\hline Budd-Chiari-Syndrom & $0,0 \%$ & $2,8 \%$ & $1,0 \%$ \\
\hline Z.n. antiviraler Therapie & $0,8 \%$ & $1,4 \%$ & $1,0 \%$ \\
\hline $\begin{array}{l}\text { Ischämische } \\
\text { Cholangiopathie }\end{array}$ & $1,6 \%$ & $1,4 \%$ & $1,6 \%$ \\
\hline $\begin{array}{l}\text { Z.n. } \\
\text { Pfortaderthrombose }\end{array}$ & $0,8 \%$ & $1,4 \%$ & $1,0 \%$ \\
\hline Hämochromatose & $0,0 \%$ & $1,4 \%$ & $0,5 \%$ \\
\hline Caroli-Syndrom & $0,0 \%$ & $1,4 \%$ & $0,5 \%$ \\
\hline med.-toxisch & $1,6 \%$ & $0,0 \%$ & $1,0 \%$ \\
\hline HEV & $0,8 \%$ & $0,0 \%$ & $0,5 \%$ \\
\hline PBC & $14,8 \%$ & $0,0 \%$ & $9,3 \%$ \\
\hline Fettleber & $11,5 \%$ & $0,0 \%$ & $7,2 \%$ \\
\hline Stauungsleber & $0,8 \%$ & $0,0 \%$ & $0,5 \%$ \\
\hline
\end{tabular}

Unterteilt man das Kollektiv zunächst in die beiden Gruppen von Patienten mit und ohne Ösophagusvarizen, so zeigt sich eine unterschiedliche Wahrscheinlichkeit von Ösophagusvarizen entsprechend der Ätiologie bzw. den Angaben zur Hepatopathie. Die verschiedenen Ätiologien wurden in der Abbildung 3-2 entsprechend der Wahrscheinlichkeit für die Abwesenheit von Ösophagusvarizen aufgeführt.

$\mathrm{Zu}$ beachten an dieser Darstellung ist jedoch, dass einige Erkrankungen, wie zum Beispiel das Caroli-Syndrom, sehr selten auftreten. Somit machen nur wenige Patienten bis hin zu einem einzigen Patienten in dieser Betrachtungsweise eine Gruppe der Ätiologie aus. Daher werden im Folgenden die Patientenzahlen zur Ätiologie differenziert aufgeführt. 
$\square$ mit Ösophagusvarizen $\square$ ohne Ösophagusvarizen

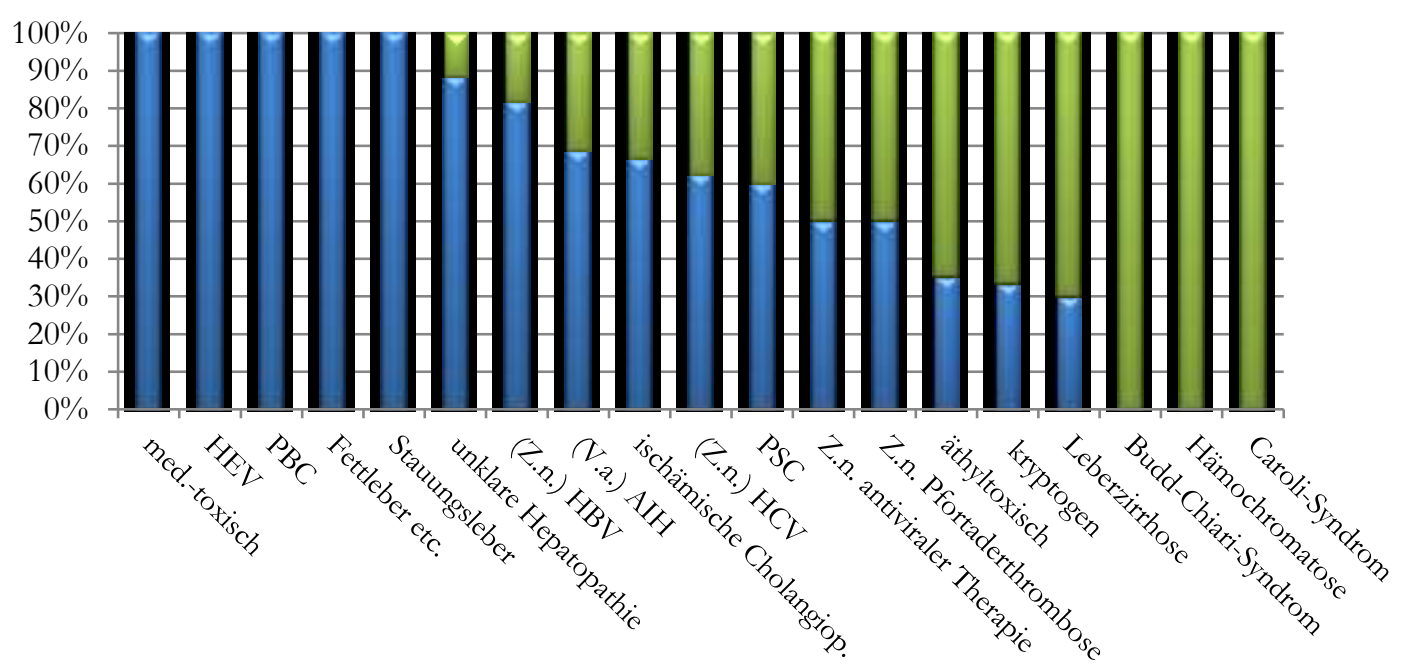

Abbildung 3-2: Vorhandensein von Ösophagusvarizen abhängig von der Ätiologie

Tabelle 3-3: Verteilung der Patienten ohne bzw. mit Ösophagusvarizen abhängig von der Ätiologie der Lebererkrankung

\begin{tabular}{|l|l|l|l|}
\hline Ätiologie & ohne Ösophagusvarizen & mit Ösophagusvarizen & Gesamtkollektiv \\
\hline unklare Hepatopathie & 23 & 3 & 26 \\
\hline äthyltoxisch & 18 & 33 & 51 \\
\hline PBC & 18 & 0 & 18 \\
\hline (Z.n.) HCV & 15 & 9 & 24 \\
\hline Fettleber; NASH & 14 & 0 & 14 \\
\hline (V.a.) AIH & 11 & 5 & 16 \\
\hline (Z.n.) HBV & 9 & 2 & 11 \\
\hline kryptogen & 4 & 8 & 12 \\
\hline Leberzirrhose & 3 & 7 & 10 \\
\hline PSC & 3 & 2 & 5 \\
\hline med.-toxisch & 2 & 0 & 2 \\
\hline ischämische Cholangiop. & 2 & 1 & 3 \\
\hline HEV & 1 & 0 & 1 \\
\hline Z.n. antiviraler Therapie & 1 & 1 & 2 \\
\hline Z.n. Pfortaderthrombose & 1 & 1 & 2 \\
\hline Stauungsleber & 1 & 0 & 1 \\
\hline Budd-Chiari-Syndrom & 0 & 2 & 2 \\
\hline Hämochromatose & 0 & 1 & 1 \\
\hline Caroli-Syndrom & 0 & 1 & 1 \\
\hline
\end{tabular}




\subsubsection{Präsenz von Ösophagusvarizen im Kollektiv}

Von den Patienten, bei denen Ösophagusvarizen beschrieben wurden, sind diese bei $43 \%$ ersten Grades, bei 44\% zweiten Grades und die übrigen 13\% drittgradig. Bei der alleinigen Betrachtung der Patienten mit Ösophagusvarizen wurde nebenbefundlich bei 74\% auch eine hypertensive Gastropathie beschrieben, gegenüber $14 \%$ bei denjenigen ohne Ösophagusvarizen.

\subsubsection{Histologische Befunde im Kollektiv}

Bei insgesamt 102 Patienten der 194 Patienten gab es außerdem eine dokumentierte Leberbiopsie mit histologischem Ergebnis, was einem prozentualen Anteil von 52,6\% des Gesamtkollektivs entspricht. Der Anteil an Patienten mit dokumentierter Leberbiopsie betrug in der Untergruppe der Patienten mit nachgewiesenen Ösophagusvarizen 48,6\% entsprechend 35 von 72 Patienten. Bei den Patienten ohne Ösophagusvarizen (122 Patienten) gab es bei 54,9\% (67 Patienten) eine Leberbiopsie. Betrachtet man die Untergruppe mit Ösophagusvarizen separat, so fand sich bei diesen Patienten mit dokumentierter Leberbiopsie bei 28,6\% (10 Patienten) eine Fibrose und bei 62,9\% (22 Patienten) eine Zirrhose. Bei entsprechender Analyse der Patienten ohne Ösophagusvarizen besteht bei 29,9\% eine Fibrose (20 Patienten) und bei 19,4\% (13 Patienten) eine Zirrhose.

\subsection{Assoziation sonographischer Parameter mit dem Vorliegen von Ösophagusvarizen}

\subsubsection{Gallenblasenwanddicke}

3.2.1.1 Auswertung der Gallenblasenwanddicke abhängig von vorhandenen Ösophagusvarizen

Bei allen Patienten wurde die Gallenblasenwanddicke sonographisch bestimmt und aus zwei Messungen der Mittelwert berechnet. In der Gesamtgruppe ist der Mittelwert der Wanddicke 3,36 mm. Bei alleiniger Betrachtung der Patienten mit Ösophagusvarizen beträgt der Mittelwert 4,36 mm, bei denen ohne Nachweis von Varizen 2,78 mm, was einen statistisch signifikanten Unterschied ausmacht $(\mathrm{p}<0,0001)$. In der Abbildung 3-3 werden die beiden Gruppen als Boxplot gegenübergestellt mit Darstellung von Minimalwert, 25\%-Perzentile, Median, 75\%-Perzentile und Maximumwert.

Unterteilt man die Ösophagusvarizengruppe weiter abhängig vom Varizengrad, so kann der Mittelwert bei erstgradiger Varizenbeschreibung mit 4,25 mm, bei zweitgradiger mit 4,51 mm und bei drittgradiger mit 4,22 $\mathrm{mm}$ berechnet werden. 


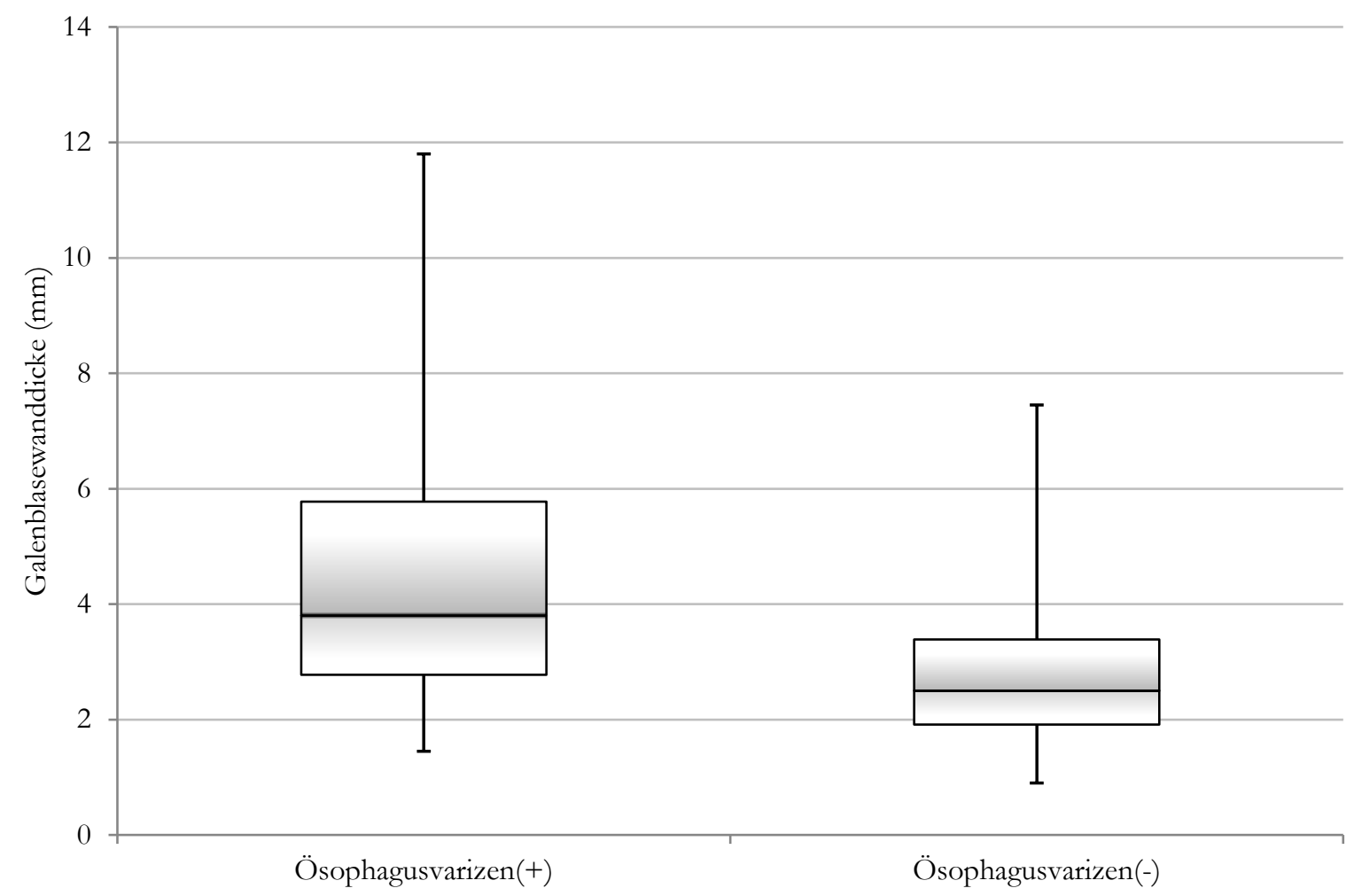

Abbildung 3-3: Boxplot zur Gallenblasenwanddicke in der Gruppe mit und der ohne Ösophagusvarizen.

\section{Mittelwert der Gallenblasenwanddicke}

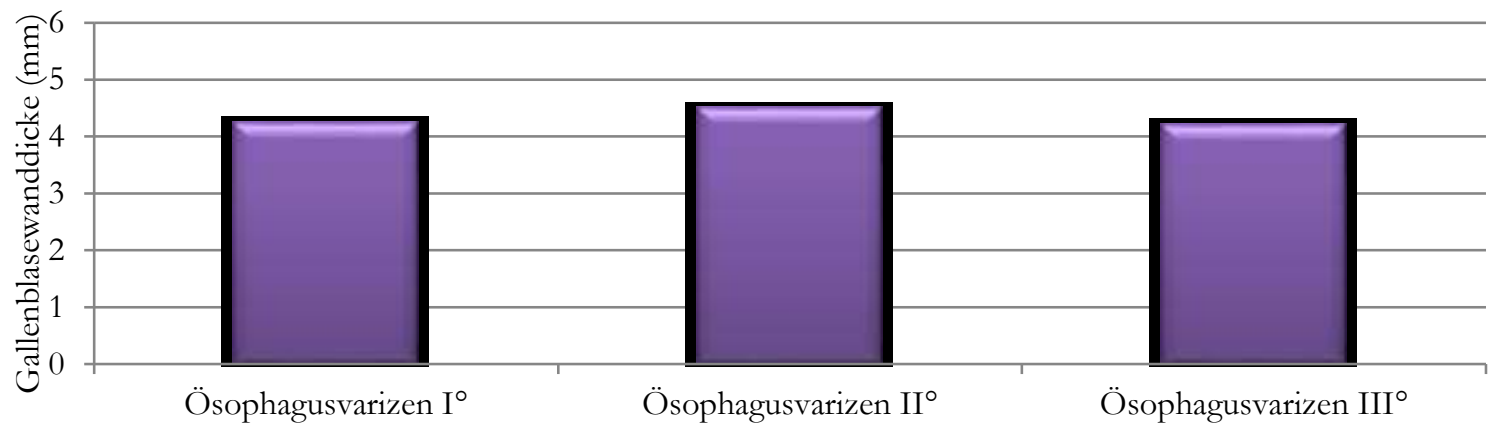

Abbildung 3-4: Vergleich der Mittelwerte (Angaben in Millimeter) der Gallenblasenwanddicke abhängig vom Schweregrad der Ösophagusvarizenausprägung

Wenn man die Gallenblasenwanddicke ab einer Ausmessung von 4mm und mehr als auffällig betrachtet, so macht dieser Anteil bei den Patienten mit Ösophagusvarizen einen Anteil von $46 \%$, bei denen ohne Ösophagusvarizen von $11 \%$ aus.

Die Sensitivität einer Wanddicke von vier und mehr Millimetern auf das Vorhandensein von Ösophagusvarizen beträgt somit $46 \%$ bei einer Spezifität von $89 \%$. Der positiv prädiktive Wert beträgt $70 \%$ und der negativ prädiktive Wert $73 \%$. 


\subsubsection{Auswertung einer Gallenblasenwandverdickung in Assoziation mit anderen} Faktoren

Bei der Auswertung der Daten mit Unterteilung in eine Gruppe mit Gallenblasenwandverdickung über vier Millimeter und in eine weitere Gruppe mit einer Gallenblasenwand bis einschließlich vier Millimeter beträgt die Anzahl mit einer sonographisch nachgewiesenen Wandverdickung 46 der insgesamt 192 Patienten.

Nimmt man diese Aufteilung als Ausgangssituation, so ist eine Gallenblasenwandverdickung über vier Millimeter in 30,4\% nicht mit Ösophagusvarizen assoziiert, während dieser Anteil bei den Patienten ohne Wandverdickung 74,0\% ausmacht. Der Anteil erstgradiger Ösophagusvarizen macht bei vorhandener Wandverdickung 30,4\% aus, gegenüber 11,6\% bei fehlender Verdickung. Der untersuchte nicht-invasive Parameter der Gallenblasenwandverdickung ist in 39,1\% der untersuchten Patienten mit höhergradigen Varizen verbunden. Ein sonographischer Normalbefund diesbezüglich war lediglich bei 15,8\% mit höhergradigen Varizen assoziiert.

Auch konnte eine hypertensive Gastropathie bei 73,9\% der Patienten mit Gallenblasenwandverdickung endoskopisch beschrieben werden, während dieses bei 24,7\% ohne Wandverdickung vermerkt wurde.

Eine Übersicht über den Vergleich der sonographisch ermittelten Parameter nach Unterteilung abhängig von der Gallenblasenwanddicke vermittelt folgende Tabelle:

Tabelle 3-4: Korrelation der Gallenblasenwanddicke mit anderen sonographischen Parametern

\begin{tabular}{|l|l|l|}
\hline Parameter & Gallenblasenwand $\leq 4 \mathbf{~ m m}$ & Gallenblasenwand > 4 mm \\
\hline Pfortaderdurchmesser & $11,78 \pm 2,17 \mathrm{~mm}$ & $2,10 \pm 3,19 \mathrm{~mm}$ \\
\hline Pfortaderflussgeschwindigkeit & $17,69 \pm 4,05 \mathrm{~cm} / \mathrm{s}$ & $19,03 \pm 6,29 \mathrm{~cm} / \mathrm{s}$ \\
\hline Milzlänge & $118,67 \pm 27,63 \mathrm{~mm}$ & $134,43 \pm 27,30 \mathrm{~mm}$ \\
\hline
\end{tabular}

Betrachtet man die Gruppe mit einer beschriebenen Gallenblasenwandverdickung, so verteilt sich diese Gruppe nahezu gleichmäßig auf die Gruppen nach der Child-Pugh-Klassifikation. Die Untergruppe im Stadium Child-A macht 32,6\% aus, gegenüber 30,4\% im Stadium B und 37,0\% im Stadium C. Im Vergleich dazu besteht bei fehlender sonographisch beschriebener Wandverdickung in 91,1\% der Fälle ein Child-A-Stadium. Der Anteil mit ermitteltem ChildB-Stadium ergibt in dieser Gruppe 6,2\%, die mit Child-C-Stadium ergibt 4,1\%.

Dazu passend zeigen sich deutliche Unterschiede in den errechneten Durchschnittswerten der Laborwerte. Der Unterschied im INR-Wert zwischen den beiden Gruppen ist hochsignifikant $(\mathrm{p}$-Wert $<0,0001)$ mit einem INR-Mittelwert von 1,47 bei einer Gallenblasenwandverdickung gegenüber 1,12 bei fehlender Verdickung. Der Kreatinindurchschnittswert ist mit $0,88 \mathrm{mg} / \mathrm{dl}$ im unauffälligen Bereich beim Fehlen eines 
pathologischen Befundes der Gallenblasenwand, dem gegenüber liegt der Durchschnittswert in der Gruppe mit Wandverdickung bei $1,15 \mathrm{mg} / \mathrm{dl}$ (p-Wert 0,038). Ein signifikanter Unterschied fand sich auch bei der Betrachtung der Thrombozytenzahl (p-Wert 0,040), die mit $157.000 / \mu$ bei pathologischer Gallenblasenwanddicke deutlich niedriger liegt als der Durchschnitt von $201.000 / \mu$ l bei unauffälliger Wanddicke.

Eine Übersicht über die Laborwerte bei Unterteilung der Patienten abhängig von einer Gallenblasenwanddicke bietet die folgende Tabelle:

Tabelle 3-5: Korrelation der Gallenblasenwanddicke mit laborchemischen Parametern

\begin{tabular}{|l|l|l|l|}
\hline Parameter & $\begin{array}{l}\text { Gallenblasenwand } \leq \\
\text { 4mm }\end{array}$ & $\begin{array}{l}\text { Gallenblasenwand }> \\
\text { 4mm }\end{array}$ & p-Wert \\
\hline $\begin{array}{l}\text { Thrombozyten } \\
\left(10^{3} / \mu \mathrm{l}\right)\end{array}$ & $200,62 \pm 89,89$ & $156,93 \pm 130,02$ & 0,040 \\
\hline INR & $1,12 \pm 0,41$ & $1,47 \pm 0,42$ & $<0,0001$ \\
\hline Kreatinin $(\mathrm{mg} / \mathrm{dl})$ & $0,88 \pm 0,32$ & $1,15 \pm 0,82$ & 0,038 \\
\hline
\end{tabular}

Der Anteil an Patienten mit Pfortaderthrombose oder starkem Verdacht auf das Vorliegen einer Pfortaderthrombose ist deutlich höher bei Vorliegen einer Gallenblasenwandverdickung mit 13,0\% gegenüber 2,7\% in der Vergleichsgruppe.

Ein wesentlicher Unterschied in Bezug auf beschriebene Lymphknoten perihilär konnte zwischen den beiden Gruppen nicht verzeichnet werden. So sind Lymphknoten in dieser Lokalisation bei 8,9\% mit einer Gallenblasenwandverdickung beschrieben, gegenüber 5,5\% ohne vorhandene Wandverdickung.

Bei fehlender Wandverdickung konnte auch in 94,5\% der Patienten eine Abwesenheit von Aszites beschrieben werden. In 37,0\% der Patienten mit Gallenblasenwandverdickung konnte ebenfalls kein Aszites nachgewiesen werden. Bei auffälliger Gallenblasenwanddicke wurde in 21,7\% wenig Aszites und in 41,3\% viel Aszites beschrieben.

Es wurde außerdem die Untergruppe der Patienten, bei denen eine Histologie durch eine Leberbiopsie dokumentiert war, untersucht. Dabei fand sich bei einer Gallenblasenwandverdickung bei 18 von 46 Patienten eine Histologie, was einem prozentualen Anteil von 64,3\% entspricht. Bei nicht pathologischer Wanddicke wurde bei 84 von 144 Patienten eine Histologie dokumentiert, entsprechend einem Anteil von 56,8\%. Von den Patienten mit Gallenblasenwandverdickung und vorhandener Histologie bestätigte sich histologisch bei 22,2\% (4 Patienten) eine Fibrose und bei 61,1\% (11 Patienten) eine Zirrhose.

Bei fehlender Wandverdickung wurde bei 31,0\% (26 Patienten) eine Fibrose bestätigt und bei 28,6\% (24 Patienten) eine Zirrhose. 


\subsubsection{Gallenblasengröße bestimmt in maximaler Längs- und Querausdehnung}

Die durchschnittliche Gallenblasenlänge wies keinen signifikanten Unterschied zwischen der Gruppe ohne und der mit Ösophagusvarizen auf, mit einer ermittelten Durchschnittslänge von 61,6 und 61,1 mm respektiv (p-Wert $=0,87$ ). Ähnlich verhält es sich mit der Gallenblasenbreite, die einen Mittelwert von $25,0 \mathrm{~mm}$ bei Abwesenheit von Ösophagusvarizen aufwies, und einen von $27,1 \mathrm{~mm}$ bei Nachweis von Varizen (p-Wert = $0,13)$.

\subsubsection{Sonographische Zeichen des Leberparenchymumbaus}

Bei jedem Patienten wurde von den Untersuchern systematisch nach Zeichen des Leberparenchymumbaus wie z. B. unregelmäßige Oberfläche, inhomogenes Leberparenchym oder vergrößerter Lobus caudatus gesucht. Eine Einteilung erfolgte in nicht vorhandene Zeichen für fortgeschrittenen Leberparenchymumbau und sonographischer Vereinbarkeit mit fortgeschrittener Leberschädigung. Insgesamt wurde in dem Gesamtkollektiv bei 94 von 194 Patienten ein Umbau beschrieben, entsprechend 48,5\%. Der Anteil lag deutlich höher bei den Patienten mit Ösophagusvarizen. In dieser Gruppe konnte sonographisch ein fortgeschrittener Leberumbauprozess bei 84,7\% beschrieben werden, gegenüber 27,0\% in der Vergleichsgruppe. Die Sensitivität bezüglich der Assoziation mit Ösophagusvarizen lag somit bei $84,7 \%$ bei einer Spezifität von 73,0\%. Wenn man die Patienten abhängig von der Ausprägung von Ösophagusvarizen separat betrachtet, so konnte bei allen Patienten mit drittgradigen Ösophagusvarizen sonographisch Zeichen des Leberparenchymumbaus beschrieben werden, gegenüber 81,3\% bei zweitgradigen Varizen, $83,9 \%$ bei erstgradigen und $27,1 \%$ bei Abwesenheit von Ösophagusvarizen.

\subsubsection{Pfortaderdurchmesser}

Die Ermittlung des Pfortaderdurchmessers wies einen Unterschied zwischen den beiden Gruppen auf, der mit einem p-Wert von 0,045 signifikant ist. So ist der errechnete Mittelwert des Pfortaderdurchmessers in der in Bezug auf Ösophagusvarizen negativen Gruppe 11,55 $\mathrm{mm}$, in der diesbezüglich positiven Gruppe 12,38 mm. Bei einer weiteren Unterteilung entsprechend der Größeneinteilung der Ösophagusvarizen nach Paquet konnte keine Korrelation zwischen dem Durchmesser und der Wahrscheinlichkeit der Ösophagusvarizenausprägung gefunden werden. Bei erstgradigen Varizen entspricht der Durchschnittswert 11,67 mm, bei zweitgradigen 13,04 $\mathrm{mm}$ und bei drittgradigen 12,45 $\mathrm{mm}$.

\subsubsection{Pfortaderflussgeschwindigkeit}

Es konnte zwischen den beiden nach Vorhandensein von Ösophagusvarizen sortierten Gruppen kein signifikanter Unterschied in Bezug auf die Pfortaderflussgeschwindigkeit ermittelt werden mit einem Durchschnittswert von $17,95 \mathrm{~cm} / \mathrm{s}$ bei 
Ösophagusvarizennachweis und einem Wert von 17,98 cm/s bei Fehlen von Varizen ( $\mathrm{p}$ Wert $=0,968)$.

Eine Flussumkehr wurde bei insgesamt drei Patienten dokumentiert. Zwei wiesen auch Ösophagusvarizen auf, so dass in dieser Gruppe der Anteil 2,8\% entspricht. In der Vergleichsgruppe ohne Ösophagusvarizen entspricht der Nachweis einer Flussumkehr bei einem Patienten einem prozentualen Anteil von 0,8\%.

Eine Pfortaderthrombose war bei sieben Patienten in der Gruppe mit Ösophagusvarizen sonographisch angenommen worden, dabei bestand bei zwei der starke Verdacht und bei einem Patienten nur eine partielle Thrombose. Dieses macht zusammen genommen einen Anteil von 9,7\% aus. In der Gruppe ohne Ösophagusvarizen war bei einem Patienten eine partielle Thrombose beschrieben worden, was einem Anteil von $0,8 \%$ ausmacht.

\subsubsection{Milzlänge}

Eine Splenektomie war bei einem der 72 Patienten mit Ösophagusvarizen in der Vergangenheit erfolgt. In der Vergleichsgruppe bestand bei 4 Patienten der Zustand nach Splenektomie, bei denen bei einem Patienten eine deutlich hypertrophierte Nebenmilz bestand, die jedoch nicht in die Auswertung mit einbezogen wurde. Eine weitere Milz konnte auf Grund der sehr weit thorakal gelegenen Lage nicht ausgemessen werden.

Von den verbliebenen verwertbaren Messungen wurde ein Vergleich zwischen den Gruppen erstellt. Hier wurde jegliche Messung mit einer Länge von $130 \mathrm{~mm}$ und mehr als hinweisend auf eine portale Hypertension betrachtet. Eine bei dieser Betrachtungsweise vergrößerte Milz konnte von allen Patienten bei 35\% beschrieben werden. In der Untergruppe der Patienten mit Ösophagusvarizen steigt der Anteil auf 62\% im Vergleich zu 19\% bei denen ohne Ösophagusvarizennachweis. In der Abbildung 3-5 wird die Gruppe mit Ösophagusvarizennachweis derjenigen ohne Ösophagusvarizennachweis als Boxplot gegenübergestellt. Dabei werden das Minimum, die 25\%-Perzentile, der Median, die 75\%Perzentile und das Maximum aufgeführt. 


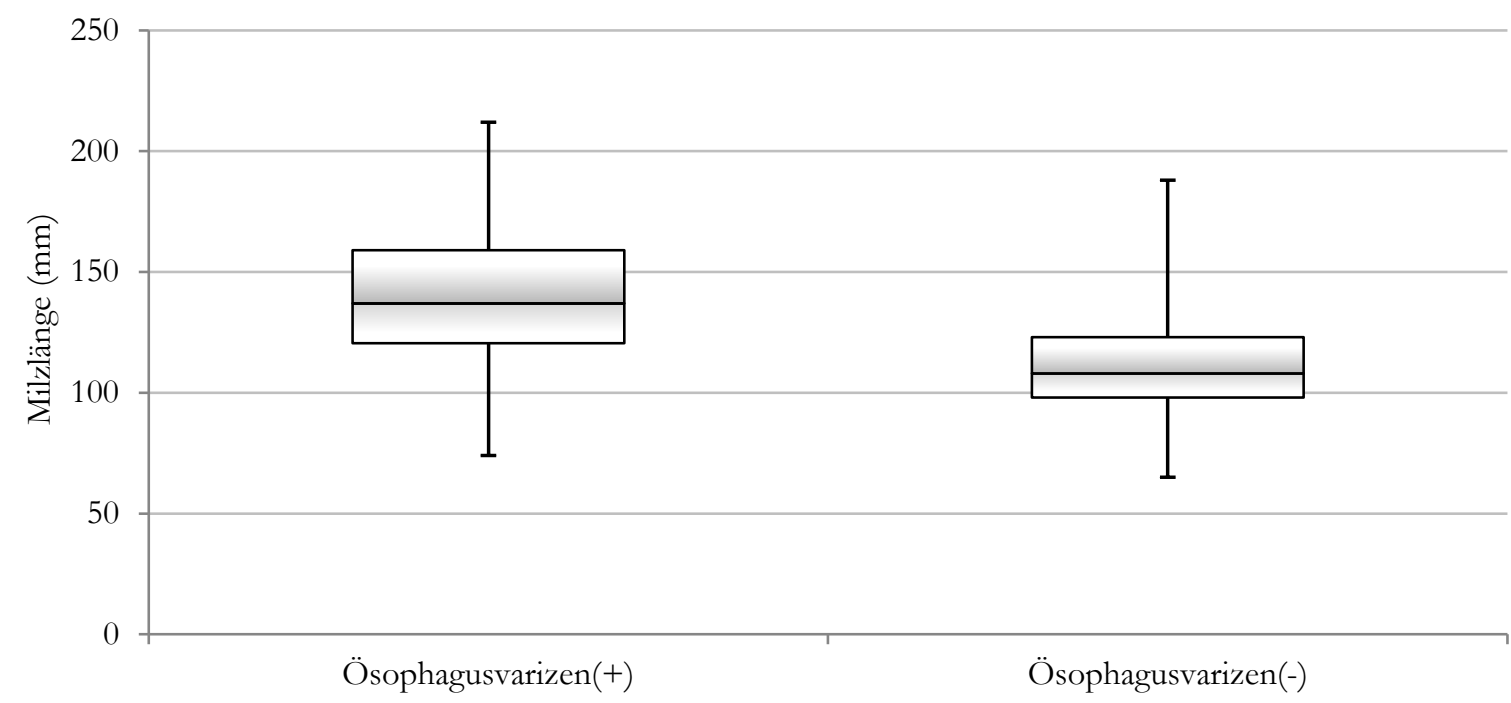

Abbildung 3-5: Auswertung der Milzlänge als Boxplot der Gruppe mit und der ohne Ösophagusvarizen.

Die errechnete durchschnittliche Milzlänge ist bei weiterer Unterteilung der Patienten mit Ösophagusvarizen umso länger, je höhergradig die Varizen beschrieben wurden. So ist der Milzlängenmittelwert bei gleichzeitig endoskopisch unauffälligem Befund hinsichtlich Varizen $113 \mathrm{~mm}$, bei Varizennachweis $138 \mathrm{~mm}$ (p-Wert < 0,0001). Bei erstgradigen Varizen steigt der Mittelwert auf $130 \mathrm{~mm}$, bei zweitgradigen auf $141 \mathrm{~mm}$ bis hin zu $156 \mathrm{~mm}$ bei drittgradiger Beschreibung.

\section{Mittelwert der Milzlänge (mm)}

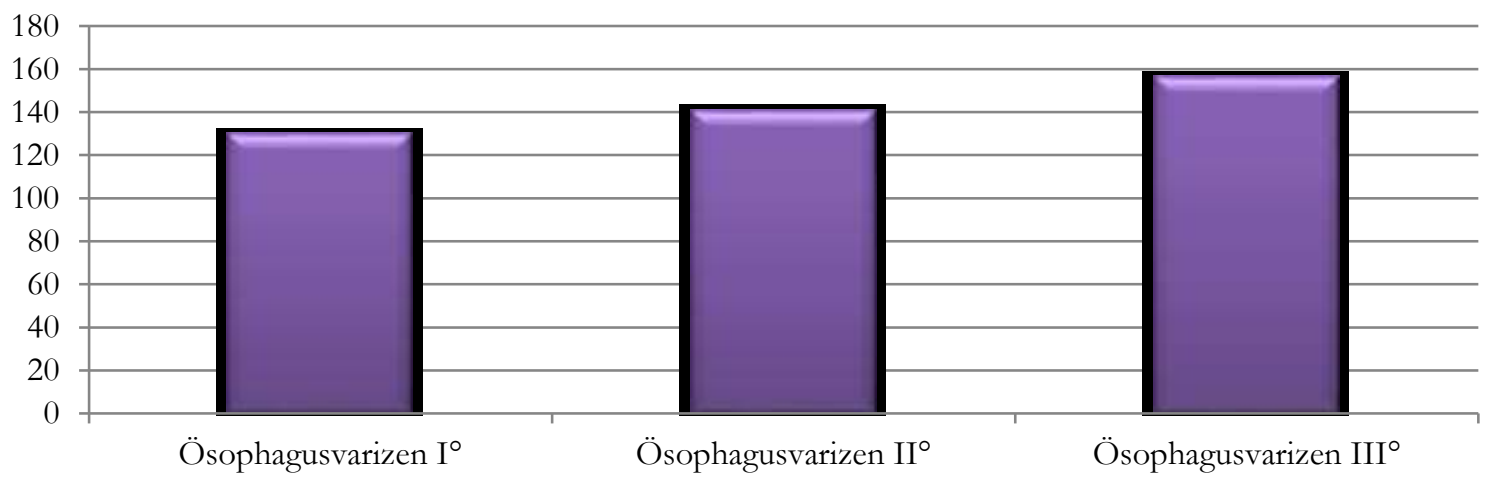

Abbildung 3-6: Vergleich der Milzlänge (Angabe in Millimeter) abhängig vom Schweregrad der Ösophagusvarizen nach Paquet

Die Sensitivität der Milzlänge größer oder gleich $130 \mathrm{~mm}$ ist somit $62 \%$ bei einer Spezifität von $81 \%$. Der positiv prädiktive Wert wurde mit $67 \%$, der negativ prädiktive Wert mit $78 \%$ berechnet. 


\subsubsection{Aszites}

Jegliches Vorhandensein von Aszites wurde bei 20\% aller Patienten beschrieben. Aszites war bei 44\% der Patienten mit Ösophagusvarizen auffällig und bei $6 \%$ der übrigen Patienten (p $<0,0001)$

Die Sensitivität von Aszites als Hinweis auf Ösophagusvarizen beträgt 44\% gegenüber einer Spezifität von $94 \%$. Der negativ prädiktive Wert beträgt $74 \%$, der positiv prädiktive Wert $82 \%$.

\subsection{8 Übersicht über sonographische Parameter}

Eine getrennte Aufführung der Mittelwerte der sonographisch messbaren Parameter der Leber und der Gallenblase wird in der folgenden Tabelle aufgeführt:

Tabelle 3-6: Sonographisch bestimmte Parameter abhängig vom Ösophagusvarizennachweis mit Angabe von Mittelwert und Standardabweichung

\begin{tabular}{|l|l|l|l|}
\hline Parameter & $\begin{array}{l}\text { Ösophagusvarizen } \\
(-)\end{array}$ & $\begin{array}{l}\text { Ösophagusvarizen } \\
(+)\end{array}$ & p-Wert \\
\hline Gallenblasenwanddicke & $2,8 \pm 1,2 \mathrm{~mm}$ & $4,4 \pm 2,1 \mathrm{~mm}$ & $<0,0001$ \\
\hline Gallenblasenlänge & $61,6 \pm 17,6 \mathrm{~mm}$ & $61,1 \pm 21,8 \mathrm{~mm}$ & 0,867 \\
\hline Gallenblasendicke & $25,0 \pm 8,6 \mathrm{~mm}$ & $27,1 \pm 10,0 \mathrm{~mm}$ & 0,128 \\
\hline Lebergröße in MCL & $13,8 \pm 2,1 \mathrm{~cm}$ & $14,7 \pm 2,6 \mathrm{~cm}$ & 0,015 \\
\hline Pfortaderdurchmesser & $11,6 \pm 2,1 \mathrm{~mm}$ & $12,4 \pm 2,9 \mathrm{~mm}$ & 0,045 \\
\hline Pfortaderflussgeschwindigkeit & $18,0 \pm 3,9 \mathrm{~cm} / \mathrm{s}$ & $18,0 \pm 5,8 \mathrm{~cm} / \mathrm{s}$ & 0,968 \\
\hline Milzlänge & $112,9 \pm 23,9 \mathrm{~mm}$ & $138,0 \pm 28,2 \mathrm{~mm}$ & $<0,0001$ \\
\hline
\end{tabular}

\subsection{Assoziation laborchemischer Werte mit dem Vorhandensein von Ösophagusvarizen.}

\subsubsection{Thrombozyten}

Betrachtet man die Patienten bezüglich einer Thrombozytenzahl von weniger als 160.000 pro Mikroliter als hinweisend auf eine portale Hypertension, so ergeben sich folgende Ergebnisse:

Ein Anteil von weniger als dem Grenzwert wurde bei insgesamt 40\% aller Patienten bestimmt, jedoch bei $69 \%$ mit gleichzeitig vorhandenen Ösophagusvarizen und $22 \%$ ohne Ösophagusvarizen. 


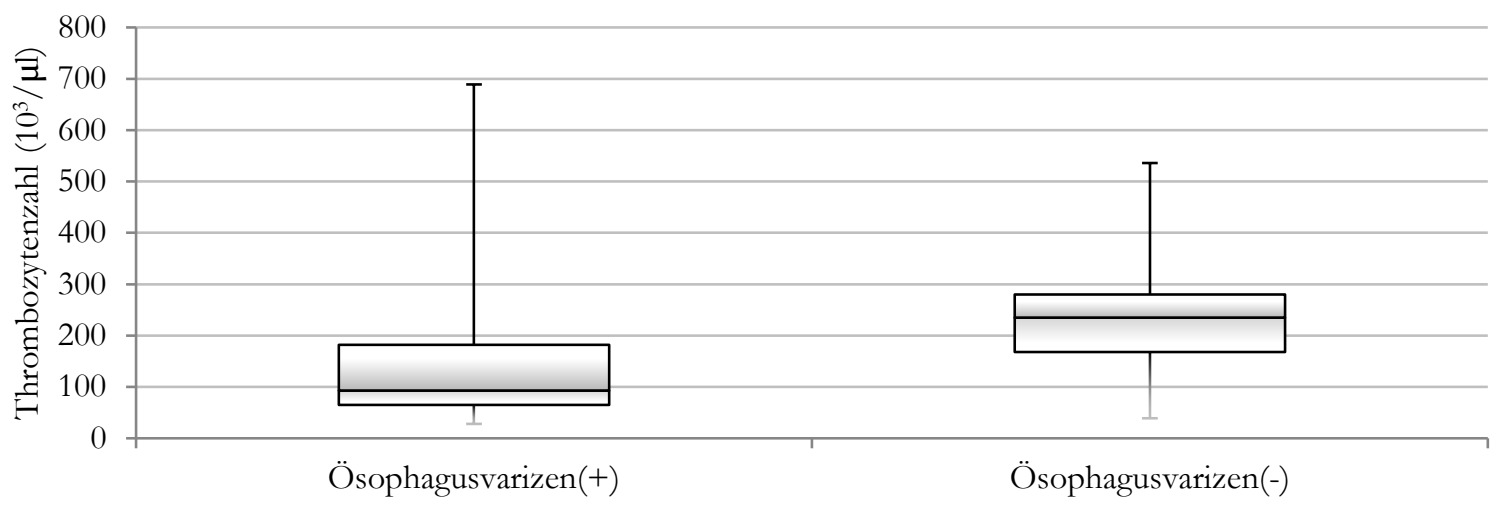

Abbildung 3-7: Vergleich der Thrombozytenzahl (in $\times 10^{3} / \mu \mathrm{l}$ ) als Boxplot zwischen der Gruppe mit und der ohne Ösophagusvarizen

Der Mittelwert des gesamten Kollektivs betrug 190.000 pro Mikroliter, in der Varizenpositiven Gruppe 128.000 und in der Varizen-negativen Gruppe 227.000 pro Mikroliter (pWert < 0,0001). In der Abbildung 3-7 werden die beiden Gruppen als Boxplot verglichen. Dabei kommen Minimum, 25\%-Perzentile, Median, 75\%-Perzentile und Maximum zur Darstellung. Bei weiterer Aufteilung wird für die Patienten mit erstgradigen Varizen ein Mittelwert von 132.000, für die mit zweitgradigen Varizen einer von 131.000 und für die mit drittgradigen einer von 105.000 pro Mikroliter bestimmt.

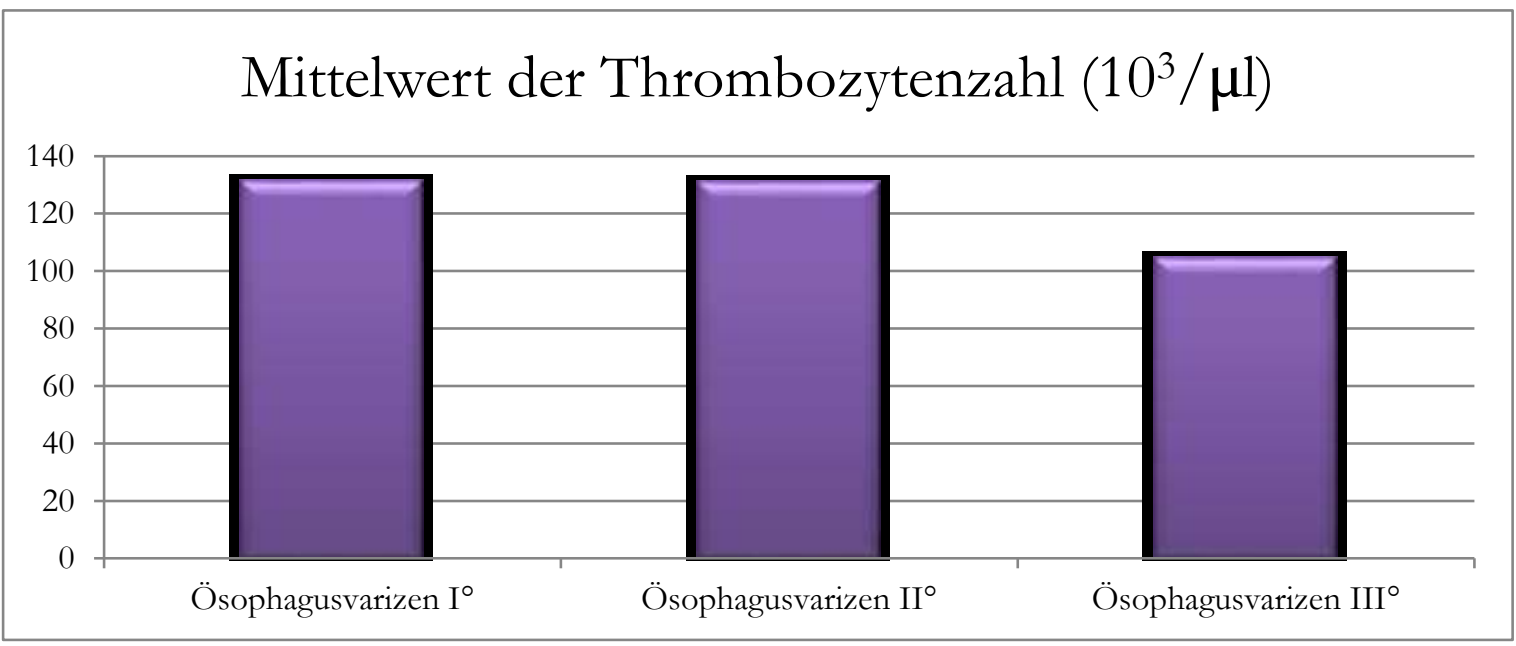

Abbildung 3-8: Vergleich der Mittelwerte der Thrombozytenzahl (in x $10^{3} / \mu \mathrm{l}$ ) abhängig vom Ausprägungsgrad der Ösophagusvarizen nach Paquet

Die Sensitivität der Thrombozytenzahl kleiner als 160.000 pro Mikroliter beträgt $69 \%$ und die Spezifität 78\%. Der negativ prädiktive Wert konnte mit $81 \%$, der positiv prädiktive Wert mit $64 \%$ berechnet werden. 


\subsubsection{INR-Wert}

Beim INR-Wert besteht ein signifikanter Unterschied zwischen den beiden Gruppen (pWert $<0,0001)$ bei einem Durchschnittswert von 1,4 in der Gruppe mit Ösophagusvarizen gegenüber 1,1 bei der ohne Nachweis von Ösophagusvarizen.

\subsection{3 Übersicht über laborchemische Parameter}

In der folgenden Tabelle wird die Auswertung der zuvor aufgeführten laborchemischen Parameter gegenübergestellt.

Tabelle 3-7: Laborchemische abhängig vom Ösophagusvarizennachweis mit Angabe von Mittelwert und Standardabweichung

\begin{tabular}{|l|l|l|l|}
\hline Parameter & $\begin{array}{l}\text { Ösophagusvarizen (- } \\
\text { ) }\end{array}$ & Ösophagusvarizen $(+)$ & p-Wert \\
\hline Thrombozyten in $10^{3} / \mu \mathrm{l}$ & $226,6 \pm 85,9$ & $128,1 \pm 99,2$ & $<0,0001$ \\
\hline INR & $1,09 \pm 0,38$ & $1,39 \pm 0,45$ & $<0,0001$ \\
\hline
\end{tabular}

\subsection{Assoziation hypertensive Gastropathie mit dem Vorhandensein von Ösophagusvarizen}

Es wurde jeweils in derselben endoskopischen Untersuchung auch makroskopische Veränderungen passend zu einer hypertensiven Gastropathie beurteilt. Dabei wurde nach Einschätzung des Endoskopeurs bei $74 \%$ der Patienten mit ebenso vorliegenden Ösophagusvarizen Veränderungen im Sinne einer hypertensiven Gastropathie beschrieben. Eine hypertensive Gastropathie ohne gleichzeitig vorhandene Ösophagusvarizen wurde in $14 \%$ der Fälle beschrieben. Der Unterschied ist somit hochsignifikant ( $p<0,0001)$.

\subsection{Assoziation des Child-Pugh-Score mit dem Vorhandensein von Ösophagusvarizen}

Nach Berechnung eines Punkte-Scores nach den Child-Pugh-Kriterien wurde jedem Patienten angelehnt an die Stadien einer Gruppe A, B oder C zugewiesen. Insgesamt gehören der Gruppe A 76\% aller Patienten an, der Gruppe B und C jeweils 12\%. 


\section{Child-Pugh-Stadium}

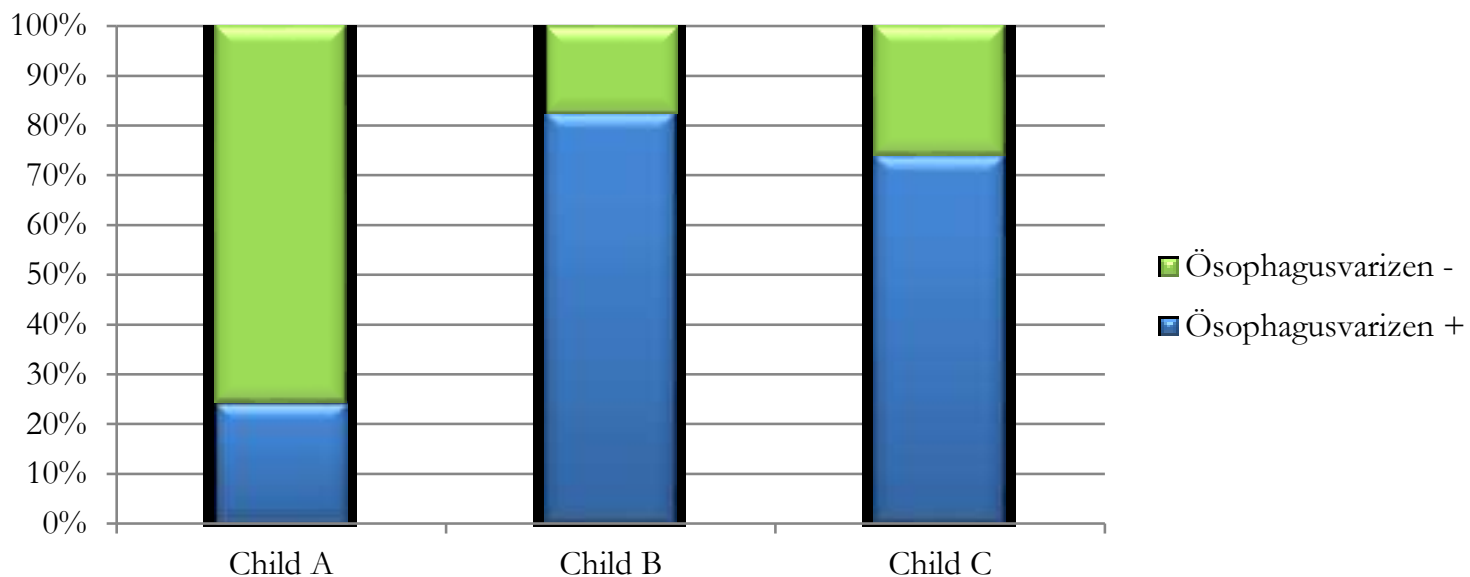

Abbildung 3-9: Aufteilung der Patienten nach Child-Pugh-Klassifikation mit Angabe des prozentualen Anteils des Ösophagusvarizennachweis

Wenn man die Ösophagusvarizen nach ihrer Ausprägung aufteilt, so besteht bei Abwesenheit von Ösophagusvarizen in 91,8\% der Fälle ein Child-A-Stadium, bei 3,3\% ein Child-B- und bei 4,9\% ein Child-C-Stadium. Bei erstgradigen Varizen ist die entsprechende Verteilung im Child-A-Stadium 54,8\%, gegenüber 25,8\% und 19,4\% in den Child-B- und CStadien respektive. Der Anteil an Child-A-Patienten ist etwas kleiner bei Ösophagusvarizen zweiten Grades mit 50,0\%. Die Child-B- und Child-C-Patienten machen bei zweitgradigen Varizen 28,1\% beziehungsweise $21,9 \%$ aus. Drittgradige Varizen konnten in 33,3\% mit Child-A-Stadium, 22,2\% mit Child-B- und 44,4\% mit Child-C-Stadium beschrieben werden. Dieses ist in der Tabelle 3-8 aufgeführt.

Tabelle 3-8: Unterteilung der Patienten abhängig von der Ösophagusvarizenausprägung sowie der Child-Pugh-Klassifikation.

\begin{tabular}{|c|c|c|c|c|c|}
\hline \multicolumn{3}{|c|}{$\begin{array}{c}\text { Keine Ösophagusvarizen } \\
122(62,9 \%)\end{array}$} & \multicolumn{3}{|c|}{$\begin{array}{c}\text { Ösophagusvarizen vorhanden } \\
72(37,1 \%)\end{array}$} \\
\hline $\begin{array}{c}\mathrm{A} \\
112(91,8 \%) \\
\end{array}$ & $\begin{array}{c}\mathrm{B} \\
4(3,3 \%)\end{array}$ & $\begin{array}{c}C \\
6(4,9 \%)\end{array}$ & $\begin{array}{c}\mathrm{A} \\
36(50,0 \%) \\
\end{array}$ & $\begin{array}{c}\mathrm{B} \\
19(26,4 \%) \\
\end{array}$ & $\begin{array}{c}\mathrm{C} \\
17(23,6 \%) \\
\end{array}$ \\
\hline \multicolumn{3}{|c|}{ Ösophagusvarizen $\mathrm{I}^{\circ}$} & $17(54,8 \%)$ & $8(25,8 \%)$ & $6(19,4 \%)$ \\
\hline \multicolumn{3}{|c|}{ Ösophagusvarizen $\mathrm{II}^{\circ}$} & $16(50,0 \%)$ & $9(28,1 \%)$ & $7(21,9 \%)$ \\
\hline \multicolumn{3}{|c|}{ Ösophagusvarizen III $^{\circ}$} & $3(33,3 \%)$ & $2(22,2 \%)$ & $4(44,5 \%)$ \\
\hline
\end{tabular}




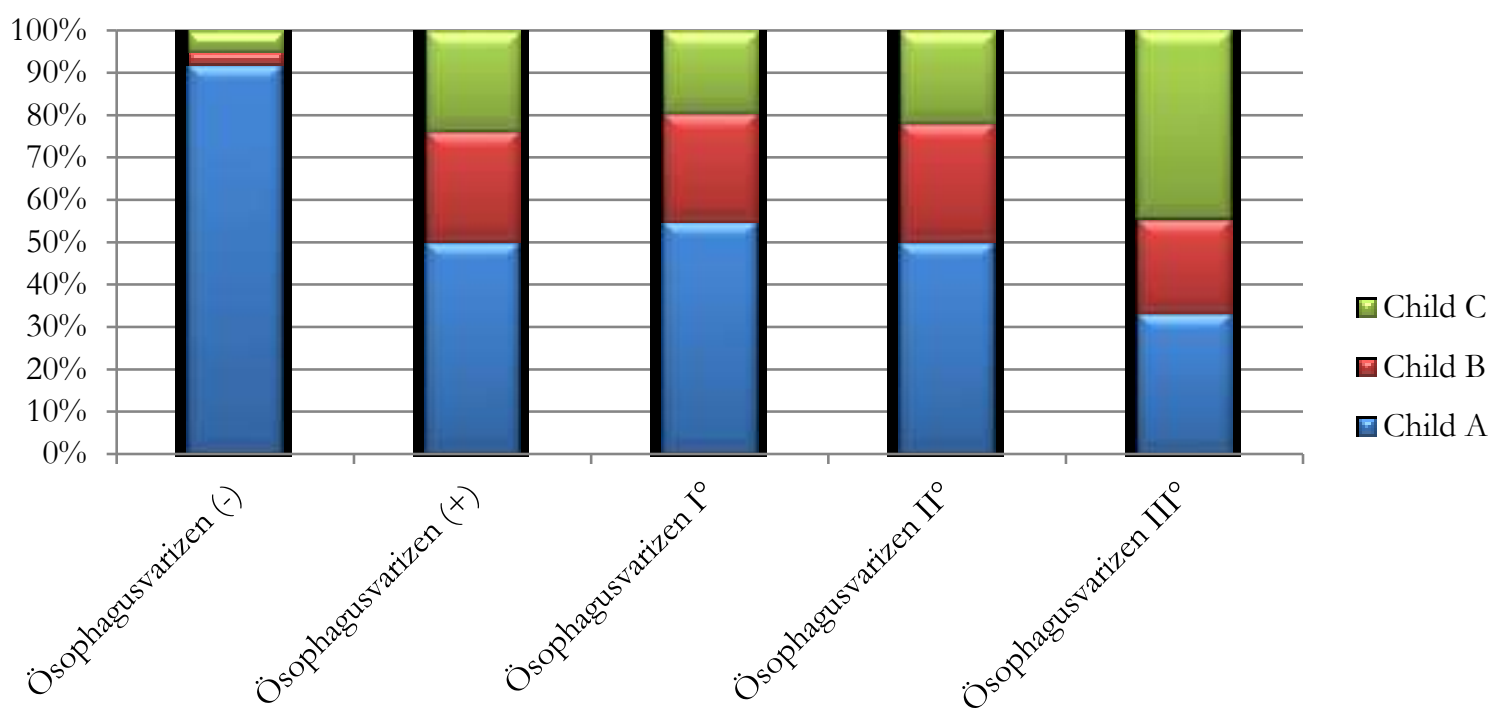

Abbildung 3-10: Einteilung der Patienten nach Child-Pugh-Klassifikation abhängig von der Ausprägung von Ösophagusvarizen

\subsection{Multivariate Analyse}

Die Auswertung der bisher aufgeführten Parameter wurde in Hinblick auf deren Signifikanz in Bezug auf den Zusammenhang mit Ösophagusvarizen bewertet. Die als signifikant ( $p<$ 0,05) eingestuften Parameter gingen in die multivariate Analyse mittels binär logistischer Regression ein (Fahrmeir et al. 2009). Folgende Parameter wurden einbezogen: Geschlecht, Child-Pugh-Score, hypertensive Gastropathie, Lebergröße, Milzlänge, INR, Thrombozytenzahl, Aszites und Pfortaderdurchmesser. Dabei konnten die Gallenblasenwanddicke, Aszites, Thrombozytenzahl und Milzlänge als unabhängige Variablen für das Vorhandensein von Ösophagusvarizen bestätigt werden.

Die Ergebnisse der binär logistischen Regression werden im Folgenden aufgeführt. Dabei entspricht B dem Regressionskoeffizient, S.E. entspricht dem Standarderror, df entspricht dem Freiheitsgrad, $\mathrm{p}$ entspricht dem $\mathrm{p}$-Wert, OR steht für Odds Ratio und CI für Konfidenzintervall.

Tabelle 3-9: Ergebnisse der multivariaten Analyse

\begin{tabular}{|l|c|c|c|c|l|l|}
\hline & B & S.E. & df & p & OR=Exp(B) & 95\% CI für OR \\
\hline $\begin{array}{l}\text { Gallenblasen- } \\
\text { wanddicke }\end{array}$ & $-0,323$ & 0,155 & 1 & 0,037 & 0,724 & $0,534-0,977$ \\
\hline Milzlänge & $-0,023$ & 0,009 & 1 & 0,007 & 0,977 & $0,961-0,994$ \\
\hline Thrombozytenzahl & 0,009 & 0,003 & 1 & 0,001 & 1,009 & $1,004-1,015$ \\
\hline Aszites & 1,674 & 0,717 & 1 & 0,019 & 5,336 & $1,310-21,731$ \\
\hline
\end{tabular}


Bei der binär logistischen Regression wird der Einfluss der unabhängigen Variablen auf die binäre abhängige Variable über die sog. Odds Ratios $(\operatorname{Exp}(B))$ ausgedrückt. Die Odds Ratio gibt ein Verhältnis zweier Chancen an. Dabei stellt eine Odds Ratio von eins keinen Zusammenhang, eine Odds Ratio größer eins einen positiven Zusammenhang und eine Odds Ratio kleiner eins einen negativen Zusammenhang dar. Die Chance wiederum ist definiert als das Verhältnis der Eintrittswahrscheinlichkeit zur Gegenwahrscheinlichkeit eines Zustands (z.B. heißt eine Chance von eins, dass die Eintrittswahrscheinlichkeit gleich der Gegenwahrscheinlichkeit ist und somit beide Wahrscheinlichkeiten 50\% sind). Die Prüfung der Signifikanz erfolgt ebenfalls über die Odds Ratios. Schließt das Konfidenzintervall von $\operatorname{Exp}(\mathrm{B})$ den Wert eins nicht ein, so wird von einem signifikanten Einfluss ausgegangen. Dies trifft bei allen untersuchten unabhängigen Variablen zu.

Die Gallenblasenwanddicke und die Milzlänge haben eine Odds Ratio kleiner eins. Verringert sich die Gallenblasenwanddicke also, so sinkt die Chance auf das Vorhandensein von Ösophagusvarizen, wenn alle anderen Kovariablen unverändert bleiben. Fällt die Milzlänge ab, so sinkt die Chance auf das Vorhandensein von Ösophagusvarizen, wenn alle anderen Kovariablen unverändert bleiben.

Thrombozytenanzahl und Aszites haben beide eine Odds Ratio größer eins. Verringert sich die Thrombozytenanzahl, so steigt die Chance auf das Vorhandensein von Ösophagusvarizen, wenn alle anderen Kovariablen unverändert bleiben. Auch die Anwesenheit von Aszites korreliert bei ansonsten unveränderten Kovariablen mit einer höheren Wahrscheinlichkeit von Ösophagusvarizen.

\subsection{Risikoermittlung durch kombinierte Parameter}

\subsubsection{Wahrscheinlichkeit von Ösophagusvarizen abhängig von kombinierten Parametern}

Auf Grundlage der Ergebnisse wurde die Wahrscheinlichkeit für das Vorliegen von Ösophagusvarizen bei Kombination von mehreren Parametern berechnet. Zunächst betrachteten wir folgende Kriterien: Milzgröße in Millimetern größer oder gleich 130 Millimetern, Thrombozytenzahl kleiner als 160.000 pro Mikroliter sowie Child-PughStadium B oder C. Sollte einer dieser Parameter positiv ausfallen, so errechnet sich daraus eine Sensitivität in Bezug auf Ösophagusvarizen jeglicher Größe von 86,11\% bei einer Spezifität von 66,39\%. Die Hinzunahme des Vorhandenseins von Aszites als zusätzliches Kriterium verändert Sensitivität und Spezifität nicht.

Erweitert man die Kriterien - bestehend aus Milzgröße, Thrombozytenzahl und Child-PughStadium - um den weiteren Faktor der Gallenblasenwanddicke über vier Millimeter, so kann dadurch die Sensitivität auf 90,28\% gesteigert werden bei einer Spezifität von 63,11\%. 


\subsubsection{Wahrscheinlichkeit von Ösophagusvarizen nach dem Quotienten von Giannini}

Die Anwendung des Quotienten nach Giannini, bestehend aus Thrombozytenzahl durch Milzlänge, erbrachte bei Unterschreitung des angegebenen Grenzwertes von 909 eine Sensitivität von $62,86 \%$ bei einer Spezifität von $87,07 \%$ in Hinblick auf die Assoziation mit Ösophagusvarizen.

Bei der weiteren Auswertung wurde für den AUC-Wert 0.841 ermittelt (CI 0.782-0.901).

Die Auswertung durch die ROC-Analyse erbrachte an unseren Daten folgendes Ergebnis:

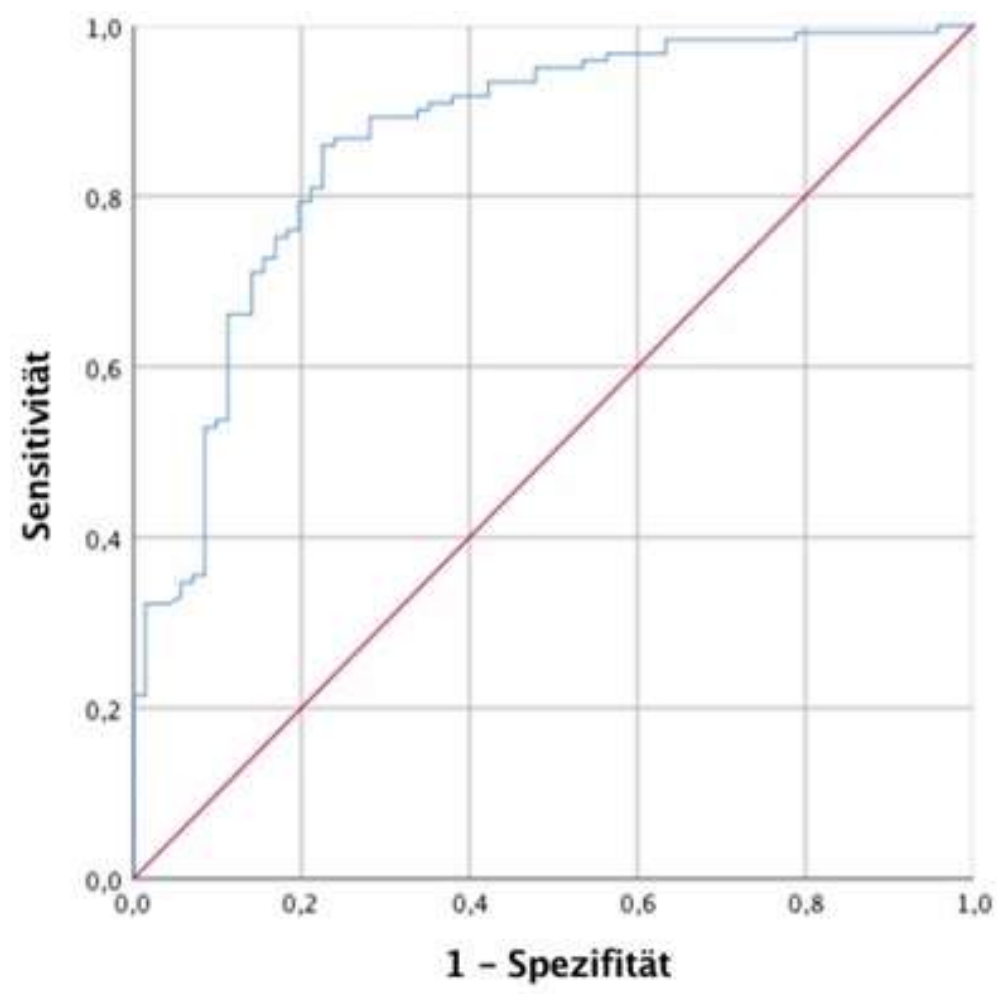

Abbildung 3-11: Grenzwertoptimierungskurve (,receiver operating characteristic” = ROC) für den Quotienten nach Giannini

\subsubsection{Wahrscheinlichkeit von Ösophagusvarizen durch die Bildung eines Quotienten aus Thrombozytenzahl und Gallenblasenwanddicke}

Auf Grund der Ermittlung einer verdickten Gallenblasenwand als unabhängiger prädiktiver Wert für das Vorhandensein von Ösophagusvarizen wurde eine Kombination mit einem anderen Faktor gesucht, die die Sensitivität der Vorhersagekraft erhöht. Dabei konnte mit der Bildung des Quotienten der Thrombozytenzahl (x103/ $\mu$ l) zur Gallenblasenwanddicke in Millimetern eine bessere Vorhersagekraft erreicht werden, die den Quotienten nach Giannini in unserem Kollektiv übertrifft. Die Sensitivität wurde mit 78\% berechnet bei einer Spezifität von $86 \%$. 
Mit der Bildung des AUC-Wertes konnte folgendes Ergebnis ermittelt werden: AUC entspricht 0.864 (CI 0.809-0.919). Im Folgenden ist die ROC-Analyse dieses Quotienten abgebildet:

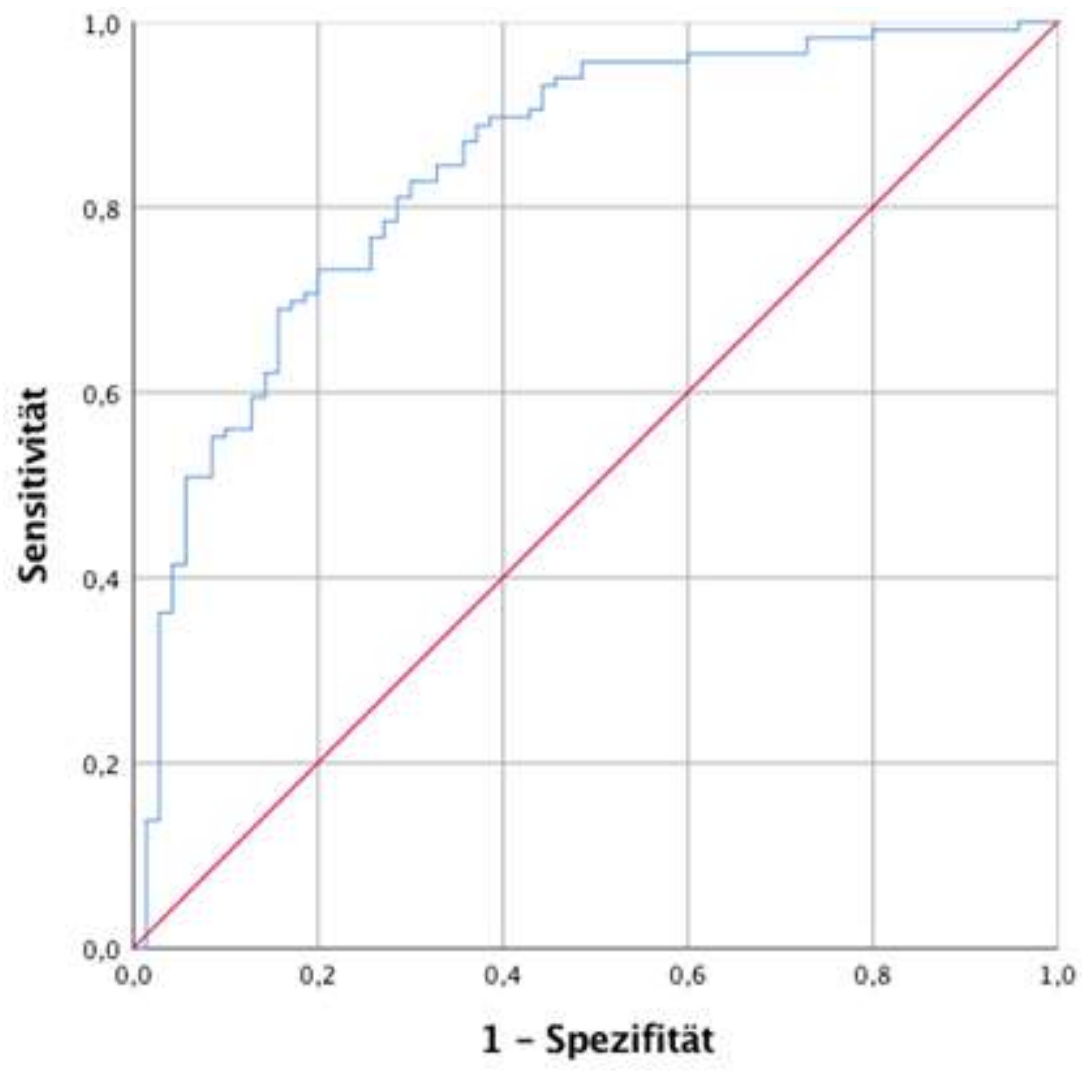

Abbildung 3-12: Grenzwertoptimierungskurve (ROC) für den Quotienten aus Gallenblasenwanddicke in Millimetern zu der Thrombozytenzahl

Als Grenzwert wurde dabei 46,2 für diesen Quotienten ermittelt. Bei einem Unterschreiten dieses Wertes ist das Vorhandensein von Ösophagusvarizen als wahrscheinlich anzunehmen.

\section{8 Übersicht der einzelnen und kombinierten Parameter im Vergleich}

Im Folgenden wird von den zuvor dargestellten Parametern die Sensitivität, Spezifität, der positiv prädiktive Wert sowie der negativ prädiktive Wert in Bezug auf die Wahrscheinlichkeit von Ösophagusvarizen jeglicher Größe aufgeführt. 
Tabelle 3-10: Vergleich der sonographischen Einzelparameter in Bezug auf die Vorhersagewahrscheinlichkeit von Ösophagusvarizen

\begin{tabular}{|c|c|c|c|c|c|}
\hline & $\begin{array}{l}\text { Gallenblasenwand- } \\
\text { dicke }(>4 \mathrm{~mm})\end{array}$ & $\begin{array}{l}\text { Milzlänge } \\
\text { ( } \geq 130 \mathrm{~mm})\end{array}$ & $\begin{array}{l}\text { Thrombozyten } \\
(<160.000 / \mu 1)\end{array}$ & Aszites & $\begin{array}{l}\text { Child- } \\
\text { Pugh B } \\
\text { oder C }\end{array}$ \\
\hline Sensitivität & $46 \%$ & $62 \%$ & $69 \%$ & $44 \%$ & $50 \%$ \\
\hline Spezifität & $89 \%$ & $81 \%$ & $78 \%$ & $94 \%$ & $92 \%$ \\
\hline $\begin{array}{l}\text { Positiv } \\
\text { prädiktiver } \\
\text { Wert }\end{array}$ & $70 \%$ & $67 \%$ & $64 \%$ & $82 \%$ & $78 \%$ \\
\hline $\begin{array}{l}\text { Negativ } \\
\text { prädiktiver } \\
\text { Wert }\end{array}$ & $73 \%$ & $78 \%$ & $81 \%$ & $74 \%$ & $76 \%$ \\
\hline
\end{tabular}

Tabelle 3-11: Vergleich von summativen Parametern in Bezug auf die Vorhersagewahrscheinlichkeit von Ösophagusvarizen

\begin{tabular}{|l|l|l|l|l|}
\hline & $\begin{array}{l}\text { GB + ML + } \\
\text { CP +Th }(\geq \mathbf{1})\end{array}$ & $\begin{array}{l}\text { ML + CP + Th } \\
(\geq \mathbf{1})\end{array}$ & $\begin{array}{l}\text { Th/Milzlänge } \\
* 1000(<\mathbf{9 0})\end{array}$ & $\begin{array}{l}\text { Th/GBWD } \\
(<46,2)\end{array}$ \\
\hline Sensitivität & $90 \%$ & $86 \%$ & $63 \%$ & $78 \%$ \\
\hline Spezifität & $63 \%$ & $66 \%$ & $87 \%$ & $86 \%$ \\
\hline $\begin{array}{l}\text { Positiv prädiktiver } \\
\text { Wert }\end{array}$ & $59 \%$ & $60 \%$ & $75 \%$ & $76 \%$ \\
\hline $\begin{array}{l}\text { Negativ prädiktiver } \\
\text { Wert }\end{array}$ & $92 \%$ & $89 \%$ & $80 \%$ & $87 \%$ \\
\hline
\end{tabular}




\section{Diskussion}

Die für diese Studie einbezogenen Patienten wiesen laborchemische Aspekte einer Lebererkrankung auf. Dabei gibt es in unserem Kollektiv unterschiedliche nachgewiesene oder wahrscheinliche Genesen der vorliegenden Lebererkrankung. So macht eine äthyltoxische Genese den wesentlichen Anteil aus, gefolgt von Hepatitis-Viren. Da in dieser Studie nicht eine histologische Untersuchung verlangt wurde, sind die Patienten nicht unterteilt in Patienten mit Zirrhose, Fibrose, entzündlichen Veränderungen oder anderweitigen Veränderungen. Wenn man davon ausgeht, dass die Patienten mit Ösophagusvarizen eher eine histologisch sicherbare Zirrhose haben, so ist der Prozentsatz mit äthyltoxischer Genese bei den Patienten mit Ösophagusvarizen von 45,8\% annähernd so hoch wie der geschätzte Anteil bei Leberzirrhose-Patienten in Deutschland von etwa 50 bis 60\% (Sauerbruch et al. 1988; Schepke et al. 2004). Von den Patienten dieser Studie mit Ösophagusvarizennachweis gab es bei 48,6\% eine dokumentierte Histologie der Leber. Dabei konnte bei 62,9\% eine Zirrhose gesichert werden, und bei weiteren 28,6\% ein fibrotischer Umbau. Beachtet werden muss dabei, dass die Histologie eher zur Unterschätzung des Fibrose- bzw. Zirrhose-Stadiums neigt (Abdi et al. 1979). Dass der Anteil mit äthyltoxischer Ursache bei den Patienten mit nachweislichen Ösophagusvarizen mit 45,8\% gegenüber 26,3\% im Gesamtkollektiv deutlich höher ist, könnte mehrere Ursachen haben. Möglich ist, dass Patienten mit äthyltoxischer Genese eher in fortgeschritteneren Stadien ärztliche Hilfe in Anspruch nehmen und somit in der Gruppe ohne Ösophagusvarizen unterrepräsentiert sind. Auch wies Fleming et al auf, dass die Prognose bei äthyltoxischer Genese schlechter ist als bei Zirrhose-Patienten anderer Genese (Fleming et al. 2012). Der prozentuale Anteil an Leberschädigungen durch äthyltoxische Genese wird mutmaßlich eher unterschätzt, da vermutlich ein kleiner Anteil der Patienten mit unklarer Hepatopathie oder kryptogener Leberzirrhose einen schädlichen Alkoholkonsum nicht angaben. Der deutlich höhere Anteil an männlichen Patienten in der Gruppe der Patienten mit Ösophagusvarizen kann ebenfalls mit dem höheren Anteil an schädlichem Alkoholkonsum unter der männlichen Bevölkerung zusammenhängen, wie es aus dem WHO-Report von 2014 hervorgeht (WHO 2014).

Ziel dieser Studie ist es, erstmals die Gallenblasenwanddicke als nicht-invasiver Surrogatparameter für das Vorliegen von Ösophagusvarizen und seine Aussagekraft zu evaluieren. Darauf aufbauend kann möglicherweise in Zukunft die Indikation zur invasiven Diagnostik mittels Gastroösophagoskopie weiter eingegrenzt werden. Verglichen wird die Aussagekraft mit den gut etablierten Parametern aus dem laborchemischen sowie klinischen Bereich in Form des Child-Pugh-Scores.

Abhängig von der Verlässlichkeit dieser nicht-invasiven Parameter kann die derzeit geltende Empfehlung, das Zeitintervall einer Kontrollgastroskopie abhängig vom letztmalig 
beschriebenen endoskopischen Befund bzw. abhängig vom Child-Pugh-Stadium festzulegen, gegebenenfalls durch nicht-invasive Parameter mehr individualisiert werden. So zeigte eine getrennte Betrachtung der Patienten mit Ösophagusvarizen $\mathrm{II}^{\circ}$ in unserer Studie, dass 50\% dieser der Child-A-Gruppe angehören. Wenn man bedenkt, dass auch bei Ösophagusvarizen $\mathrm{II}^{\circ}$ bei Vorliegen von Risikofaktoren wie red spots die Indikation zur Ligatur gestellt werden kann, so ist möglicherweise bei alleiniger Risikostratifizierung nach den Child-Pugh-Kriterien der Abstand von 2 Jahren für einige diese Patienten zu lang. Selbst von den Patienten mit Ösophagusvarizen III $^{\circ}$ wurde ein Drittel als Child-A klassifiziert. Möglicherweise ist eine mehr auf den individuellen Patienten angepasste Festlegung des zeitlichen Abstandes zwischen zwei Gastroskopien mittels zusätzlicher Parameter eine Option. Bei im Rahmen des HCC-Screenings erforderlichen halbjährlichen sonographischen Untersuchungen kann in Kombination mit Laborwerten eine halbjährliche nicht-invasive Risikobeurteilung erfolgen. Auf dieser Grundlage ist eine Verlängerung oder Vorziehung von endoskopischen Untersuchungsintervallen zu diskutieren. Bisher konnten sich nicht-invasive Kriterien zur Risikoeinschätzung des Vorliegens von Ösophagusvarizen in der Klinik nicht durchsetzen. Die nun erstmalig untersuchte Gallenblasenwanddicke als zusätzlichen Marker kann wesentlich zur weiteren Risikobeurteilung und somit Indikationsstellung zur invasiven Diagnostik sein.

\subsection{Untersuchung der Gallenblasenwanddicke als indikativer Parameter für das Vorhandensein von Ösophagusvarizen}

Die Gallenblase ist auf Grund ihrer besonderen Blutversorgung interessant in Hinblick auf das gleichzeitige Vorhandensein von Ösophagusvarizen bei portaler Hypertension. Die Blutversorgung der Gallenblase erfolgt durch die Arteria cystica, welche in der Regel ein Abgang aus dem rechten Ast der Arteria hepatica propria ist. Der venöse Abfluss erfolgt in der Regel im Wesentlichen in die Pfortader sowie im kleineren Anteil direkt in die Leber. Bei einer portalen Hypertension ist daher eine Zunahme der Gallenblasenwanddicke auf Grund des gestörten Abflusses gehäuft zu beobachten (Johnston und Anson 1952).

Wegen der höheren Wahrscheinlichkeit des Vorhandenseins von Ösophagusvarizen bei dekompensierter Leberzirrhose ist der höhere Anteil an Patienten mit Aszites in der Untergruppe mit Varizennachweis plausibel. Die multivariate Analyse konnte die Gallenblasenwanddicke als unabhängigen Prädiktor für Ösophagusvarizen identifizieren, so dass die Verdickung durch die Anwesenheit von Aszites nicht ausreichend erklärt ist und die erläuterte Blutversorgung wahrscheinlicher als ursächlich erscheint. Die Untersuchung von 152 Patienten mit Leberzirrhose durch Li et al. wies nach, dass eine Verminderung der Pfortaderflußgeschwindigkeit mit einer Verdickung der Gallenblasenwand assoziiert ist (Li et al. 2010). Dieses Ergebnis spricht für die pathophysiologische Bedeutung der Gefäßversorgung der Gallenblase für die Wandverdickung. Eine Hypalbuminämie konnte in einer Untersuchung von Colli an 47 Patienten mit Aszites nicht mit einer verdickten 
Gallenblasenwand assoziiert werden. Er wies jedoch eine Korrelation des Gradienten von Albumin im Serum zu Albumin im Aszites mit einer verdickten Gallenblasenwand nach, was als weitere Erklärung in Betracht gezogen werden muss (Colli et al. 1991a).

Bisher gibt es jedoch keine Untersuchung der Assoziation einer verdickten Gallenblasenwand mit dem Vorliegen von Ösophagusvarizen bei Erwachsenen. Daher ist die hier vorgestellte Untersuchung zur Ermittlung der Relevanz der Gallenblasenwanddicke als hinweisenden Parameter auf Ösophagusvarizen erfolgt, um erstmalig einen Zusammenhang zu untersuchen.

Hierzu war zunächst die Festlegung des Grenzwertes der Gallenblasenwanddicke bezüglich der Wahrscheinlichkeit von außerdem vorhandenen Ösophagusvarizen wichtig. Differentialdiagnostische Überlegungen zu einer verdickten Gallenblasenwand sind die akute sowie die chronische Cholezystitis, aber auch eine postprandiale physiologische Zunahme des Durchmessers. Bezüglich Hinweis auf chronische oder akute Cholezystitis wird ein Grenzwert von 3mm angegeben (Majeski 2007). Auch als Abgrenzung zu Gallenblasenwandverdickungen im Rahmen einer portalen Hypertension wird $3 \mathrm{~mm}$ und mehr als pathologisch angenommen (de Alcantara et al. 2013a). Bei jedoch außerdem möglicher physiologischer Wandverdickung postprandial von bis zu $4 \mathrm{~mm}$, wurde in dieser Studie ein Wert über $4 \mathrm{~mm}$ als auffällig angesehen. So ist das Ergebnis auch nicht wesentlich durch die Abhängigkeit vom Zeitpunkt zur letzten Nahrungsaufnahme beeinflusst. Außerdem bestand bei keinem der Patienten ein gezielter Druckschmerz der Gallenblase oder ein hinreichender Verdacht auf das Vorliegen einer Cholezystitis.

In einer Studie von Loreno konnte sonographisch bei 23 Child-Pugh-A-Patienten eine mittlere Gallenblasenwanddicke von 0,60 \pm 0,22 cm gegenüber einer Wanddicke von 0,21 \pm $0,06 \mathrm{~cm}$ bei Gesunden beschrieben werden (Loreno et al. 2009). Damit zeigte sich der Mittelwert der Gallenblasenwanddicke in dieser Studie höher als in der hier vorgestellten Untersuchung, obwohl alle Patienten der Studie von Loreno lediglich als Child-Pugh-A eingestuft wurden. Die Gallenblasenwanddicke wurde bei diesen Patienten nur nüchtern gemessen, was die Diskrepanz nicht erklärt. Daher muss die Genese möglicherweise auch mit einbezogen werden, sowie die geringe Anzahl der untersuchten Patienten der LorenoStudie, die vorwiegend eine virale Genese (69,5\%) der Erkrankung, weniger eine äthyltoxische Genese (17,4\%) aufwiesen.

De Alcantara ermittelte eine Sensitivität von 60\% bei einer Spezifität von $90 \%$ bei einem Cut-off-Wert der Gallenblasenwanddicke von $\geq 4,35 \mathrm{~mm}$ für das Vorhandensein von Ösophagusvarizen bei Patienten mit chronischer Lebererkrankung. Bei einer weiteren Patientengruppe mit extrahepatischer portalvenöser Obstruktion konnte bei einer Wanddicke $\geq 3,3 \mathrm{~mm}$ mit einer Sensitivität von 90,9\% und einer Spezifität von 100\% noch eine deutlich bessere Assoziation nachgewiesen werden (de Alcantara et al. 2013a). Da diese Genese jedoch in Westeuropa eher einen geringen Anteil der Ursachen einer portalen Hypertonie ausmacht, sind die Ergebnisse nicht mit dieser Studie vergleichbar. Auch 
untersuchte De Alcantara in der Studie ausschließlich Patienten in einem Alter von unter 20 Jahren, so dass auch dadurch unterschiedliche Resultate begründet sind.

Bei genauerer Betrachtung der Ösophagusvarizengruppe in der hier vorgestellten Untersuchung kann der Mittelwert bei erstgradiger Varizenbeschreibung mit 4,25 mm, bei zweitgradigen mit 4,51 $\mathrm{mm}$ und bei drittgradigen mit 4,22 $\mathrm{mm}$ berechnet werden. Ein Rückschluss auf die Ausprägung der Ösophagusvarizen kann somit nicht aus der Gallenblasenwanddicke geschlossen werden, die Wahrscheinlichkeit für das Vorliegen von Ösophagusvarizen kann jedoch durch diesen Parameter besser eingeschätzt werden. Daher ist die Einbeziehung der Gallenblasenwanddicke als zusätzlichen nicht-invasiven Marker zur Einschätzung der Ösophagusvarizenwahrscheinlichkeit sinnvoll.

\subsection{Untersuchung weiterer sonographischer Aspekte als indikative Parameter für das Vorhandensein von Ösophagusvarizen}

\subsubsection{Gallenblasengröße}

Die Gallenblasengröße erscheint interessant, da eine Beeinflussung der Kontraktilität bei Patienten mit fortgeschrittener Lebererkrankung von anderen Autoren vorbeschrieben wurde. Diese erscheint postprandial deutlich weniger ausgeprägt zu sein bei ZirrhosePatienten gegenüber gesunden Patienten, wie mittels Choleszintigraphie aufgezeigt werden konnte. Dieses führt auch zu einer höheren Prävalenz von Cholezystolithiasis (Hao et al. 2015). Die Genese ist nicht eindeutig geklärt. Sonographisch konnte auch eine gestörte Koordination der Magenentleerung und der Gallenblasenentleerung nachgewiesen werden, mit frühzeitiger beginnender Gallenblasenfüllung bei Patienten mit Zirrhose (Acalovschi et al. 1997).

Beim Vergleich der Gallenblasenlänge und der Gallenblasenbreite in Längsdarstellung konnte in unserer Studie kein relevanter Unterschied zwischen den Patienten mit und denen ohne Ösophagusvarizen nachgewiesen werden. Die sonographische Bestimmung der Gallenblasengröße ist oftmals durch die variable Erscheinung der Gallenblase erschwert. So ist bei einer nicht selten darstellbaren Gallenblase in Form einer Phrygischen Mütze die Ausmessung der Gallenblase deutlich schwerer.

\subsubsection{Sonographische Ermittlung der Lebergröße}

In der Regel wird bei einer sonographischen Untersuchung der Leber die Lebergröße erfasst, die jedoch auf Grund der speziellen Form der Leber fehleranfälliger in der Ausmessung ist als viele andere abdominelle Organe. Auch wird nicht von jedem Untersucher eine Ausmessung in der Medioclavicularlinie durchgeführt, sondern alternativ eine Ausmessung aus der Position der vorderen Axillarlinie bevorzugt. Diese ist weniger anfällig von Luftüberlagerung, kann aber an sich nicht mit der Messung in Medioklavilularlinie verglichen 
werden. Ist eine Messung in üblicher Position in MCL möglich, so kann sowohl ein Abweichen vom senkrechten Winkel zur Unterlage als auch ein stärkeres oder weniger tiefes Einatmen als die übliche mittlere Inspirationstiefe Abweichungen begünstigen. Eine Hypertrophie der Leber, die zu einer weiten Verlagerung der Leber nach links mit teils längerstreckigem Kontakt der Leber zur Milz führt, ist nicht zwingend mit einer deutlichen Hypertrophie in der MCL verbunden. Daher wird dieser Parameter nicht als verlässliches Zeichen für eine Leberschädigung angesehen, auch da eine Leberschädigung selbst bei Vorliegen von Leberzirrhose sowohl mit einer Hypertrophie als auch mit einer hypotroph erscheinenden Leber verbunden sein kann. Entsprechend zeigt sich in der Auswertung unserer Daten ein geringer Unterschied zwischen der Gruppe mit Ösophagusvarizen und der ohne Ösophagusvarizen. Bei der Varizen-negativen Gruppe konnte eine Größe der Leber in MCL von 13,8 cm als Mittelwert errechnet werden. In der Gruppe mit Ösophagusvarizen-Nachweis beträgt der Mittelwert 14,7 cm.

\subsubsection{Sonographische Zeichen des Leberparenchymumbaus}

Eine knotige Oberfläche wird als Zeichen der Leberzirrhose gewertet und ist folglich mit der Bildung von Ösophagusvarizen verbunden. Dabei weist diese Auffälligkeit mit einer Sensitivität von 33\% und einer Spezifität von 97\% auf das Vorliegen einer Leberzirrhose bei Patienten mit chronischer Hepatitis hin (Lee et al. 2010). Auf Grund der geringen Sensitivität der auffälligen Oberfläche alleine, wurde in unserer Studie auf weitere indirekte Zeichen für einen Leberparenchymumbau geachtet. So wurde eine generalisierte Leberparenchyminhomogenität, ein vergrößerter Lobus caudatus, eine auffällige Kontur sowie die Rarefizierung der Lebervenen oder eine hypertrophierte Arteria hepatica propria in die Beurteilung miteinbezogen. Damit konnte eine deutliche Assoziation von sonographisch darstellbaren Hinweisen für einen fortgeschrittenen Leberparenchymumbau mit dem Vorhandensein von Ösophagusvarizen gezeigt werden. Die Sensitivität des sonographisch nachweisbaren Umbauprozesses als Surrogatparameter für endoskopisch nachweisbare Ösophagusvarizen liegt bei 84\%. Die Spezifität ist mit 73\% geringer. Problematisch an diesem Faktor ist, dass er auf Grund der sehr subjektiven Einschätzung und der sehr hohen Abhängigkeit von der Untersuchererfahrenheit sowie der Geräteausstattung besonders anfällig für Fehler ist, daher ist eine hohe Schwankungsbreite bezüglich der Sensitivität zu erwarten. Die Messung der Gallenblasenwanddicke bietet demgegenüber den Vorteil, dass es ein metrischer Marker ist und somit weniger von der Erfahrung des Untersuchers abhängig ist.

\subsubsection{Milzgröße}

In den Verlaufskontrollen rasch ermittelbar ist die Milzgrößenbestimmung. Eine Splenomegalie ermittelt mit dem maximalen Durchmesser ist sowohl indikativ auf das Vorhandensein von Ösophagusvarizen als auch auf eine drohende Dekompensation bei nachgewiesener Leberzirrhose (Berzigotti et al. 2008). Bedacht werden muss, dass eine 
Splenomegalie auch mannigfaltige andere Ursachen haben kann und somit bezüglich ihrer Spezifität eher gering ist.

Gao konnte bei 106 Patienten mit Primär biliärer Zirrhose einen Mittelwert der Milzlänge von 154,0 mm bei Vorhandensein von Ösophagusvarizen gegenüber 126,1 $\mathrm{mm}$ bei Abwesenheit dieser bestimmen, bei einem durch t-Test ermittelten p-Wert von unter 0,001. In unserer Studie lag der Mittelwert in der Gruppe mit Ösophagusvarizen bei 138,0 mm und in der Vergleichsgruppe bei 112,9 mm (p-Wert < 0,001). Gao nutzte einen Grenzwert von $156 \mathrm{~mm}$ bei der Milzlänge zur Abschätzung, ob Ösophagusvarizen vorhanden sind. Dabei konnte eine Sensitivität von 47,9\% und eine Spezifität von 89,4\% berechnet werden. In unserer Studie wurde bei einer Milzlänge von $130 \mathrm{~mm}$ und mehr eine Sensitivität von 62,0\% und eine Spezifität von 81,2\% bezüglich Vorhandenseins von Ösophagusvarizen bestimmt. Die heterogenere Patientengruppe in unserer Studie erscheint als wahrscheinlichste Ursache für die abweichenden Ergebnisse zur Studie von Gao.

Die Milzlänge wies in einer Studie von Takuma 2013 bei dem Vergleichskollektiv ohne Ösophagusvarizen einen Mittelwert von $104 \mathrm{~mm}$ auf, bei den Patienten mit Ösophagusvarizen betrug der Mittelwert $131 \mathrm{~mm}$. Die Werte liegen somit in einem ähnlichen Bereich wie in unserer Studie. Das Patientenkollektiv von Takuma bestand aus 340 Patienten, von denen bei 132 Ösophagusvarizen nachweisbar waren. Die häufigste Ätiologie war eine Hepatitis-B oder Hepatitis-C-Infektion für die nachgewiesene Leberzirrhose mit einem Anteil von 251 Patienten, dennoch ist die Gruppe deutlich heterogener und eher mit unserem Patientenkollektiv vergleichbar als in der zuvor beschriebenen Studie von Gao (Takuma et al. 2013; Gao et al. 2017).

\subsubsection{Pfortaderdurchmesser und Pfortaderflussgeschwindigkeit}

Die Ausmessung der Querschnittsfläche der Pfortader kann Hinweise auf den portalen Hypertonus geben, allerdings wird sie durch die Abhängigkeit von dem Zeitabstand zur letzten Mahlzeit beeinflusst. Jedoch zeigten Sabbà et al., dass bei Patienten mit Leberzirrhose keine wesentliche Veränderung der Querschnittsfläche postprandial zum nüchternen Zustand nachweisbar war, bei der gesunden Vergleichsgruppe aber eine Größenzunahme von 22\% beobachtet werden konnte. Demgegenüber kam es sowohl bei Patienten mit Leberzirrhose als auch bei Gesunden zu einer Zunahme der Flussgeschwindigkeit postprandial um 35 bzw. 55\% (Sabbà et al. 1992). Die Abschätzung der Querschnittsfläche ist außerdem fehleranfällig durch die Berechnung aus dem ermittelten Durchmesser der Pfortader. Die Pfortadergeschwindigkeit kann direkt durch Anwendung einer CosinusFunktion errechnet werden, dabei muss jedoch die Winkelkorrektur richtig angewandt werden. Es sollte daher eine Messung mit einem Winkel größer als $60^{\circ}$ zur Ultraschallsonde unbedingt vermieden werden, um die Fehlerabweichung der Messung gering zu halten. Beide Parameter sind auf Grund der aufgeführten Einschränkungen als Verlaufskontrollen nur eingeschränkt verwendbar, da mehrere Faktoren die Messergebnisse zusätzlich zur 
Untersucher- und Geräteabhängigkeit beeinflussen (Sabbà et al. 1992). Auch besteht bei eingeschränkten Schallbedingungen sowohl die Gefahr, dass die Geschwindigkeitsmessung unbemerkt oberhalb der Pfortaderaufgabelung erfolgt, was $\mathrm{zu}$ deutlich geringeren Flussgeschwindigkeiten durch Messung im Pfortaderast führt. Schlechte Schallbedingungen können gelegentlich auch eine genauere Nachvollziehbarkeit des Pfortaderverlaufes erschweren, und somit die adäquate Winkelkorrektur nicht ermöglichen.

In unseren Daten beträgt der Pfortaderdurchmesser im Mittelwert 11,6 $\mathrm{mm}$ bei den Patienten ohne Ösophagusvarizen, und 12,4 mm bei denen mit Ösophagusvarizen (p-Wert $=0,045)$. Als Ausdruck der portalen Hypertension kann es zur Erweiterung der Pfortader kommen. Eine Überschreitung von 11,8 mm im Durchmesser weist laut Gao mit einer Sensitivität von $79 \%$ bei einer Spezifität von $62 \%$ auf Ösophagusvarizen jeglicher Größe hin (Gao et al. 2017). Bei Anwendung des Grenzwertes von 11,8 mm auf unsere Daten konnte damit eine Sensitivität von 55\% bei einer Spezifität von 51\% berechnet werden. Die Daten von Gao wurden ausschließlich von 106 Patienten mit Primär biliärer Zirrhose gewonnen, so dass auch bei diesem Parameter die Heterogenität der Gruppe unserer Studie möglicherweise zu einer deutlich geringeren Sensitivität und Spezifität geführt haben kann.

Bei einer Geschwindigkeit des hepatopetalen Pfortaderflusses von unter 12,8 cm/s ist die Wahrscheinlichkeit der drohenden oder vorhandenen Dekompensation der Leberzirrhose deutlich erhöht (Kondo et al. 2016). Eine Flussumkehr innerhalb der Pfortader ist mit einer schlechteren Prognose verbunden (Kondo et al. 2015). Unserer Erfahrung nach ist eine Pfortaderflussumkehr eine seltene Erscheinung und somit nicht als Parameter im Sinne der Fragestellung verwertbar. So konnte in diesem Patientenkollektiv bei zwei Patienten mit Ösophagusvarizen und einem Patienten ohne Nachweis von Ösophagusvarizen eine Flussumkehr dokumentiert werden.

Die Pfortaderflussgeschwindigkeit weist in unserer Studie keinen Unterschied in beiden Gruppen auf mit jeweils 18,0 cm/s, mit lediglich höherer Standardabweichung von 5,8 cm/s bei den Patienten mit Ösophagusvarizen gegenüber 3,9 cm/s in der Vergleichsgruppe. In anderen Studien konnten Unterschiede ausgemacht werden bezüglich der Flussgeschwindigkeit. So konnte in einer indischen Studie bei 56 Patienten eine signifikante Differenz ausgemacht werden ( $\mathrm{p}$-Wert 0,005) mit einem Mittelwert der Pfortaderflussgeschwindigkeit von 14,77 cm/s bei Patienten mit Varizen gegenüber 17,66 $\mathrm{cm} / \mathrm{s}$ bei Patienten ohne Varizen (Chakrabarti et al. 2016a). Li wiederum ermittelte eine mittlere Flussgeschwindigkeit der Pfortader von $14,2 \mathrm{~cm} / \mathrm{s}$ bei Patienten mit erstgradigen Ösophagusvarizen, $13,1 \mathrm{~cm} / \mathrm{s}$ bei zweitgradigen Varizen und $12,0 \mathrm{~cm} / \mathrm{s}$ bei drittgradigen Varizen. In der gesunden Vergleichsgruppe konnte $\mathrm{Li}$ eine mittlere Pfortaderflussgeschwindigkeit von 15,3 cm/s bestimmen (Li et al. 2005).

Auf Grund der eigenen Ergebnisse sowie der technisch bedingten Anfälligkeit der Messung wird die Bestimmung des Pfortaderflusses als indikativer Parameter für das Vorhandensein von Ösophagusvarizen als unzuverlässig angesehen und nicht zur Verwendung empfohlen. 
Eine Pfortaderthrombose sollte bei Neubeschreibung eine endoskopische Kontrolle bezüglich Ösophagusvarizen nach sich ziehen. In dieser Studie lag der Anteil der Patienten mit sonographisch nachgewiesener kompletter oder partieller Pfortaderthrombose sowie sonographisch stark geäußertem Verdacht auf das Vorliegen einer Pfortaderthrombose in der Ösophagusvarizen-positiven Gruppe mit $9,7 \%$ deutlich über $0,8 \%$ in der Vergleichsgruppe.

\subsection{Laborchemische Parameter}

Bei der Betrachtung des INR-Wertes zeigt sich ein signifikanter Unterschied zwischen den Gruppen mit und ohne Ösophagusvarizen. Da es in Bezug zur Gruppenzugehörigkeit abhängig vom Child-Pugh-Stadium ebenfalls deutliche Unterschiede gibt beim Vergleich der Patienten mit Varizennachweis im Gegensatz zu denen ohne, kann darauf auch ein Rückschluss auf die beinhalteten Laborparameter gemacht werden. In die Child-PughBewertung geht neben den Quick-Wert auch Albumin und Gesamtbilirubin mit ein, so dass bei diesen Werten auch von relevanten Differenzen bei Aufteilung abhängig von Varizennachweis ausgegangen werden kann. Der Kreatinin-Wert weist mit einem p-Wert von 0,049 einen signifikanten Wert zwischen den Gruppen auf. Der Kreatinin-Wert fließt nicht in den Child-Pugh-Score, jedoch in den MELD-Score mit ein. Ein Grund für den gering signifikanten Unterschied könnte im späten Auftreten einer Nierenfunktionsverschlechterung bei fortgeschrittener Leberschädigung bestehen. Bilirubin und Albuminwerte zeigen häufig im früheren Krankheitsverlauf bereits Veränderungen auf.

\subsection{Steifigkeitsmessungen als Ermittlungsverfahren von Leberstrukturumbau und portaler Hypertension}

Die Steifigkeit von Leber und Milz wird außerdem als weiterer Parameter erforscht. Dabei sind aktuell verschiedene technische Herangehensweisen möglich. Am längsten angewandt wird die Ermittlung mittels Fibroscan®. Weitere Verfahren sind ARFI, kurz für acoustic radiation force impulse, und die Shear-Wave-Elastographie. Eine höhere Steifigkeit der Leber ist dabei eher wahrscheinlich mit einem fortgeschrittenen Leberstrukturumbau assoziiert. Angenommen wird außerdem, dass eine höhere Milzsteifigkeit eher mit einer portalen Hypertension assoziiert ist. Es muss bei der Lebersteifigkeit beachtet werden, dass für unterschiedliche Genesen der Lebererkrankung auch unterschiedliche Grenzwerte für ein wahrscheinliches Vorliegen einer höhergradigen Fibrose oder Zirrhose gelten. Auch sind die Grenzwerte unterschiedlich je nach verwendetem Verfahren. Problematisch an der Anwendung ist daher auch, dass bei einigen Patienten die Genese nicht eindeutig geklärt ist, und somit nicht sicher ist, ob zum Beispiel ein Grenzwert wie bei Steatosis hepatis oder wie bei äthyltoxischer Genese angewandt werden sollte. In einigen Fällen wäre daher eine histologische Sicherung zur Abklärung der Genese der Erkrankung sinnvoller, so dass die Elastographie dann überflüssig ist. Erschwert ist die Elastographie auch dadurch, dass eine 
zu starke Signalabschwächung bei adipösen Patienten auftreten kann. Eine ausreichend mögliche Mitarbeit ist bei den Patienten nicht immer möglich, so schaffen es einige nicht ausreichend lang den Atem anzuhalten, was Fehlmessungen begünstigt. Auch wird von einigen Autoren eine Abhängigkeit vom Zeitpunkt der letzten Nahrungsaufnahme beschrieben. Insgesamt besteht somit bezüglich der Anwendung und der Verlässlichkeit der Lebersteifigkeitsmessung noch viel Untersuchungsbedarf. Auch ist für diese Diagnostik eine Geräteausstattung der neueren Generation erforderlich, die zurzeit auch in westlichen Ländern nicht flächendeckend vorhanden ist. Studien bezüglich der Assoziation von Leberoder Milzsteifigkeit mit dem Vorhandensein von Ösophagusvarizen sind bisher wenige veröffentlicht, so dass der Nutzen der erforderlichen zusätzlichen Geräteausstattung und des Zeitaufwandes noch nicht ausreichend belegt ist (Takuma et al. 2013).

\subsection{Kombinierte nicht-invasive Parameter}

\subsubsection{Quotient nach Giannini}

Die von Giannini 2003 eingeführte Quotientenbestimmung aus Milzgröße und Thrombozytenzahl soll mit hoher Sensitivität Ösophagusvarizen prädiktieren. In der Originalstudie von Giannini wurde der Quotient aus Thrombozytenzahl pro Kubikmillimeter durch Milzlänge in Millimeter gebildet. Bei den 103 Patienten mit einem überwiegenden Anteil von Hepatitis-C-Patienten (54\%) wurde die Diagnose einer Leberzirrhose entweder durch klinische, bildmorphologische und laborchemische Veränderungen oder durch eine histologische Einteilung gestellt. Bei einem Quotientenwert von kleiner oder gleich 909 konnte eine Sensitivität von 100\% bei einer Spezifität von 93\% für das Vorliegen von Ösophagusvarizen aufgewiesen werden. Ein positiv prädiktiver Wert von $96 \%$ bei einem negativ prädiktivem Wert von 100\% wurde ermittelt (Giannini et al. 2003a).

Chen untersuchte 2016 mittels einer Metaanalyse die Anwendung des Quotienten nach Giannini. Dabei kam bei der Untersuchung der Ergebnisse von 49 Veröffentlichungen eine Sensitivität von $84 \%$ bei einer Spezifität von $78 \%$ in Bezug auf Vorhandensein von Ösophagusvarizen heraus. Bei Betrachtung lediglich der viralen Leberzirrhosen konnte eine höhere Sensitivität von 92\% ermittelt werden (Chen et al. 2017a).

Bei Anwendung dieses sogenannten „platelet count-spleen diameter-ratio“ auf unsere Studie wurde eine Sensitivität von 63\% bei einer Spezifität von $87 \%$ ermittelt. Der positiv prädiktive Wert liegt bei $75 \%$, der negativ prädiktive Wert bei $80 \%$. Möglicherweise kommt die deutliche Abweichung der Sensitivität unter anderem durch die heterogenere Gruppe unserer Studie bezüglich der Ätiologie der Lebererkrankung zu Stande. Diese Begründung wird durch die zuvor erwähnten Ergebnisse von Chen gestützt. Auch war bei unserer Studie die Diagnose einer Leberzirrhose kein Einschlusskriterium. 
Schwachpunkt des Quotienten ist allerdings, dass eine Splenomegalie an sich mit einer Thrombozytopenie assoziiert sein kann, durch das sogenannte Hypersplenismus-Syndrom. Somit bringt dieser Quotient einen zusätzlichen Parameter ein, der häufig durch den ersten Parameter der Milzgröße beeinflusst wird. Ergänzend kommt es bei äthyltoxischer oder viraler Schädigung des Knochenmarks zu einer Thrombozytopenie. Auch eine verminderte Thrombopoetin-Produktion in den Hepatozyten verursacht die Thrombozytopenie zusätzlich. Eine Ergänzung durch einen nicht pathophysiologisch zum ersten Parameter verbundenen zweiten Parameter zur Risikoabschätzung erscheint sinnvoll. Dieser kann die Gallenblasenwanddicke sein, da diese pathophysiologisch betrachtet gegenüber falsch positiven Veränderungen durch hämatoonkologische und infektiös-virale Erkrankungen weniger anfällig ist als die Milzlänge und die Thrombozytenzahl.

\subsubsection{Quotient aus Thrombozytenzahl zur Gallenblasenwanddicke}

Auf Grund der Überlegungen zum Quotienten nach Giannini wurde nach alternativen Verfahren gesucht. Hierbei fand sich durch die weitere Auswertung der multivariaten Analyse, dass eine Bildung des Quotienten aus Thrombozytenzahl (in x $10^{3} / \mu \mathrm{l}$ ) durch die Gallenblasenwanddicke in Millimetern bei einem Grenzwert von 46,2 ein besseres Abschneiden in der Grenzwertoptimierngskurve aufweist als die Anwendung nach Giannini. Auch die Sensitivität liegt höher bei nur minimal niedrigerer Speizifität, was in Bezug auf Indikationsstellung zur invasiven Diagnostik mit der Frage nach Ösophagusvarizen zu favorisieren ist.

\subsubsection{Kombination von Gallenblasenwanddicke, Milzlänge, Thrombozytenzahl und Child-Pugh-Stadium}

Betrachtet man die Kriterien Gallenblasenwanddicke über vier Millimeter, Milzlänge größer oder gleich 130 Millimeter, eine Thrombozytenzahl unter 160.000 pro Mikroliter sowie ein Child-Pugh-Stadium B oder C, so kann bei positivem Ausfall eines dieser Parameter mit einer Sensitivität von 90,2\% das Vorhandensein von Ösophagusvarizen vorhergesagt werden. Die Spezifität beträgt 63,1\%. Würde man die Gallenblasenwanddicke nicht als zusätzlichen Parameter miteinbeziehen, so fällt die Sensitivität auf 86,1\% bei einer höheren Spezifität von 66,4\%. Macht man die endoskopische Untersuchung der Patienten von diesem Screening auf Ösophagusvarizen abhängig, so ist eine höhere Sensitivität bei einem geringen Abfall der Spezifität zu bevorzugen. Die Verwendung dieses Screening-Verfahrens ist ebenfalls dem Quotienten nach Giannini überlegen bei Anwendung auf dieses Patientenkollektiv mit unterschiedlichen Genesen der Lebererkrankung.

Auf Grund dieser Ergebnisse ist die Ausmessung der Gallenblasenwanddicke bei Patienten mit einer Lebererkrankung sinnvoll, da eine verdickte Gallenblasenwand ein unabhängiger Faktor in der Risikoermittlung für Ösophagusvarizen ist. In Kombination mit anderen nichtinvasiven Markern kann die Erforderlichkeit einer invasiven Diagnostik evaluiert werden. 


\section{$5 \quad$ Zusammenfassung}

Mit dieser Studie wurde erstmalig die sonographisch ermittelbare Gallenblasenwanddicke bezüglich ihrer Vorhersagekraft für Ösophagusvarizen bei erwachsenen Patienten mit einer Hepatopathie untersucht. Dafür wurden die Daten von 194 Patienten unterschiedlichen Ätiologien einer Lebererkrankung erfasst. Eine Unterteilung der Patienten erfolgte in die Untergruppen mit und ohne Vorliegen von Ösophagusvarizen, um diese bezüglich sonographischer, laborchemischer und klinischer Parameter zu vergleichen.

Bei alleiniger Betrachtung der Patienten mit Ösophagusvarizen beträgt der Mittelwert der Gallenblasenwanddicke 4,36mm, bei denen ohne Nachweis von Varizen 2,78mm. Dieser hochsignifikante Unterschied weist bereits auf die Bedeutung der Gallenblasenwanddicke als neuer nicht-invasiver Parameter hin. Eine Gallenblasenwanddicke von mehr als vier Millimeter weist eine Spezifität von $89 \%$ bei einer Sensitivität von $46 \%$ bezüglich Vorhandenseins von Ösophagusvarizen auf. Der positiv prädiktive Wert beträgt $70 \%$ und der negativ prädiktive Wert 73\%. Mittels multivariater Analyse konnte die Gallenblasenwanddicke als unabhängiger Faktor bezüglich des Vorliegens von Ösophagusvarizen bestätigt werden.

Bei Bestimmung einer Gallenblasenwanddicke von über vier Millimeter, einer Milzlänge größer oder gleich 130 Millimeter, einer Thrombozytenzahl unter 160.000 pro Mikroliter oder einem Child-Pugh-Stadium B oder C besteht bei positivem Ausfall von einem dieser Parameter eine Sensitivität von $90 \%$ bezüglich Vorliegen von Ösophagusvarizen. Die Spezifität beträgt 63\%. Ohne die Gallenblasenwanddicke als zusätzlich betrachteten Wert fällt die Sensitivität auf 86\% ab.

Durch die Bildung des Quotienten aus Thrombozytenzahl und Gallenblasenwanddicke kann bei Unterschreitung eines Wertes von 46,2 eine Sensitivität von 78\% bei einer Spezifität von $86 \%$ erreicht werden. Der bisher am ehesten angewandte, jedoch klinisch nicht etablierte Quotient nach Giannini aus Thrombozytenzahl und Milzlänge erbrachte bei Anwendung auf unser Kollektiv eine unterlegene Sensitivität von 63\% bei einer Spezifität von 87\%.

Die Ergebnisse dieser Studie konnten den positiven Zusammenhang einer Gallenblasenwandverdickung mit dem Vorliegen von Ösophagusvarizen erstmalig nachweisen. In Kombination mit anderen nicht-invasiven Markern ist die Bestimmung der Gallenblasenwanddicke daher sinnvoll zur nicht-invasiven Risikostratifizierung bezüglich des Risikos des Bestehens von Ösophagusvarizen bei Lebererkrankten. 


\section{$6 \quad$ Literaturverzeichnis}

Abdi W, Millan JC, Mezey E (1979): Sampling variability on percutaneous liver biopsy. Arch Intern Med 139, 667-669

Acalovschi M, Dumitraşcu DL, Csakany I (1997): Gastric and gall bladder emptying of a mixed meal are not coordinated in liver cirrhosis--a simultaneous sonographic study. Gut $\underline{40}$, 412-417

Agrawal S, Dhiman RK, Limdi JK (2016): Evaluation of abnormal liver function tests. Postgrad Med J 92, 223-234

Baiocchini A, Montaldo C, Conigliaro A, Grimaldi A, Correani V, Mura F, Ciccosanti F, Rotiroti N, Brenna A, Montalbano M, et al. (2016): Extracellular Matrix Molecular Remodeling in Human Liver Fibrosis Evolution. PloS One 11, e0151736

Bedossa P, Poynard T (1996): An algorithm for the grading of activity in chronic hepatitis C. The METAVIR Cooperative Study Group. Hepatology 24, 289-293

Berzigotti A, Zappoli P, Magalotti D, Tiani C, Rossi V, Zoli M (2008): Spleen enlargement on follow-up evaluation: a noninvasive predictor of complications of portal hypertension in cirrhosis. Clin Pract J Am Gastroenterol Assoc ㅁ, 1129-1134

Berzigotti A, Seijo S, Reverter E, Bosch J (2013): Assessing portal hypertension in liver diseases. Gastroenterol Hepatol 7, 141-155

Blachier M, Leleu H, Peck-Radosavljevic M, Valla D-C, Roudot-Thoraval F (2013): The burden of liver disease in Europe: a review of available epidemiological data. J Hepatol $\underline{58}$, 593-608

Bosch J, Navasa M, Garcia-Pagán JC, DeLacy AM, Rodés J (1989): Portal hypertension. Med Clin North Am $\underline{73}$, 931-953

Burroughs AK (1993): The natural history of varices. J Hepatol 17 Suppl 2, S10-13

Chakrabarti R, Sen D, Khanna V (2016): Is non-invasive diagnosis of esophageal varices in patients with compensated hepatic cirrhosis possible by duplex Doppler ultrasonography? J Indian Soc Gastroenterol $\underline{35}$, 60-66

Chen R, Deng H, Ding X, Xie C, Wang W, Shen Q (2017): Platelet Count to Spleen Diameter Ratio for the Diagnosis of Gastroesophageal Varices in Liver Cirrhosis: A Systematic Review and Meta-Analysis. Gastroenterol Res Pract 2017, 7407506

Christensen E, Fauerholdt L, Schlichting P, Juhl E, Poulsen H, Tygstrup N (1981): Aspects of the natural history of gastrointestinal bleeding in cirrhosis and the effect of prednisone. Gastroenterology $\underline{81}$, 944-952

Colli A, Cocciolo M, Buccino G, Parravicini R, Martinez E, Rinaldi G, Scaltrini G (1991): Thickening of the gallbladder wall in ascites. J Clin Ultrasound JCU 19, 357-359 
Cordero-Ruiz P, Carmona-Soria I, Rodríguez-Téllez M, Caunedo-Alvarez A, QuezadaPacheco RH, Flores-Cucho A, Romero-Gómez M, Vilches-Arenas Á (2017): Longterm follow-up of patients with chronic hepatitis $C$ treated with $\alpha$-interferon and ribavirin antiviral therapy: clinical and fibrosis impact of treatment response. Eur J Gastroenterol Hepatol 29, 792-799

D’Amico G, Luca A (1997): Natural history. Clinical-haemodynamic correlations. Prediction of the risk of bleeding. Baillieres Clin Gastroenterol 11, 243-256

D’Amico G, Pagliaro L, Bosch J (1999): Pharmacological treatment of portal hypertension: an evidence-based approach. Semin Liver Dis $\underline{19}$, 475-505

D’Amico G, Garcia-Tsao G, Pagliaro L (2006): Natural history and prognostic indicators of survival in cirrhosis: a systematic review of 118 studies. J Hepatol 44, 217-231

de Alcantara RV, Yamada RM, Cardoso SR, de Fátima M, Servidoni CP, Hessel G (2013b): Ultrasonographic predictors of esophageal varices. J Pediatr Gastroenterol Nutr $\underline{57}$, 700-703

de Franchis R, Primignani M (2001): Natural history of portal hypertension in patients with cirrhosis. Clin Liver Dis $\underline{5}, 645-663$

Desmet VJ, Gerber M, Hoofnagle JH, Manns M, Scheuer PJ (1994): Classification of chronic hepatitis: diagnosis, grading and staging. Hepatology 19, 1513-1520

Fahrmeir L, Kneib T, Lang S: Regression: Modelle, Methoden und Anwendungen. (Statistik und ihre Anwendungen), 2. Aufl; Springer, Berlin 2009

Fleming KM, Aithal GP, Card TR, West J (2012): All-cause mortality in people with cirrhosis compared with the general population: a population-based cohort study. J Int Assoc Study Liver 32, 79-84

Gao L, Meng F, Cheng J, Li H, Han J, Zhang W (2017): Prediction of oesophageal varices in patients with primary biliary cirrhosis by non-invasive markers. Arch Med Sci AMS $\underline{13}, 370-376$

Garcia-Tsao G, Sanyal AJ, Grace ND, Carey W, Practice Guidelines Committee of the American Association for the Study of Liver Diseases, Practice Parameters Committee of the American College of Gastroenterology (2007): Prevention and management of gastroesophageal varices and variceal hemorrhage in cirrhosis. Hepatology 46, 922-938

Giannini E, Botta F, Borro P, Risso D, Romagnoli P, Fasoli A, Mele MR, Testa E, Mansi C, Savarino V, et al. (2003a): Platelet count/spleen diameter ratio: proposal and validation of a non-invasive parameter to predict the presence of oesophageal varices in patients with liver cirrhosis. Gut $\underline{52}, 1200-1205$

Giannini E, Botta F, Borro P, Malfatti F, Fumagalli A, Testa E, Podestà E, Chiarbonello B, Polegato S, Mamone M, et al. (2003b): Relationship between thrombopoietin serum levels and liver function in patients with chronic liver disease related to hepatitis $\mathrm{C}$ virus infection. Am J Gastroenterol 98, 2516-2520

Groszmann RJ, Abraldes JG (2005): Portal hypertension: from bedside to bench. J Clin Gastroenterol 39 Suppl 2, S125-130 
Groszmann RJ, Garcia-Tsao G, Bosch J, Grace ND, Burroughs AK, Planas R, Escorsell A, Garcia-Pagan JC, Patch D, Matloff DS, et al. (2005): Beta-blockers to prevent gastroesophageal varices in patients with cirrhosis. N Engl J Med $\underline{353}, 2254-2261$

Hammel P, Couvelard A, O’Toole D, Ratouis A, Sauvanet A, Fléjou JF, Degott C, Belghiti J, Bernades P, Valla D, et al. (2001): Regression of liver fibrosis after biliary drainage in patients with chronic pancreatitis and stenosis of the common bile duct. N Engl J Med $\underline{344}, 418-423$

Hao R, Wang H, Li C, Yang J (2015): The role of cholescintigraphy in demonstrating delayed post prandial gallbladder motility in cirrhotic patients. Hell J Nucl Med $\underline{18}$, 122-126

Hsieh Y-C, Lee K-C, Chen P-H, Su C-I, Hou M-C, Lin H-C (2017): Acute kidney injury predicts mortality in cirrhotic patients with gastric variceal bleeding. J Gastroenterol Hepatol $\underline{32}$, 1859-1866

Infante-Rivard C, Esnaola S, Villeneuve JP (1987): Clinical and statistical validity of conventional prognostic factors in predicting short-term survival among cirrhotics. Hepatology 7, 660-664

Johnston EV, Anson BJ (1952): Variations in the formation and vascular relationships of the bile ducts. Surg Gynecol Obstet 94, 669-686

Kalafateli M, Zisimopoulos K, Vourli G, Rigamonti C, Goulis J, Manesis E, Manolakopoulos S, Tsochatzis E, Georgiou A, Diamantopoulou G, et al. (2017): Prognostic Models for Survival in Patients with Stable Cirrhosis: A Multicenter Cohort Study. Dig Dis Sci 62:1363-1372

Kondo T, Maruyama H, Sekimoto T, Shimada T, Takahashi M, Yokosuka O (2015): Reversed portal flow: Clinical influence on the long-term outcomes in cirrhosis. World J Gastroenterol 21, 8894-8902

Kondo T, Maruyama H, Sekimoto T, Shimada T, Takahashi M, Okugawa H, Yokosuka O (2016): Impact of portal hemodynamics on Doppler ultrasonography for predicting decompensation and long-term outcomes in patients with cirrhosis. Scand J Gastroenterol 1ㅡ, 236-244

Lee HS, Kim JK, Cheong JY, Han EJ, An SY, Song JH, Jung YJ, Jeon SC, Jung MW, Jang EJ, et al. (2010): Prediction of compensated liver cirrhosis by ultrasonography and routine blood tests in patients with chronic viral hepatitis. Korean J Hepatol 16, 369-375

Li C, Yang Z, Ma E, Liu Y (2010): Analysis of the correlation between the degree of GBW'T and hemodynamic changes of portal vein system. Sheng Wu Yi Xue Gong Cheng Xue Za Zhi [J Biomed Eng] 27, 583-585, 625

Li F-H, Hao J, Xia J-G, Li H-L, Fang H (2005): Hemodynamic analysis of esophageal varices in patients with liver cirrhosis using color Doppler ultrasound. World J Gastroenterol 11, 4560-4565

Loreno M, Travali S, Bucceri AM, Scalisi G, Virgilio C, Brogna A (2009): Ultrasonographic study of gallbladder wall thickness and emptying in cirrhotic patients without gallstones. Gastroenterol Res Pract 2009, 683040 
Majeski J (2007): Significance of preoperative ultrasound measurement of gallbladder wall thickness. Am Surg $\underline{73}$, 926-929

Malinchoc M, Kamath PS, Gordon FD, Peine CJ, Rank J, ter Borg PC (2000): A model to predict poor survival in patients undergoing transjugular intrahepatic portosystemic shunts. Hepatology $\underline{31}, 864-871$

Merkel C, Marin R, Angeli P, Zanella P, Felder M, Bernardinello E, Cavallarin G, Bolognesi M, Donada C, Bellini B, et al. (2004): A placebo-controlled clinical trial of nadolol in the prophylaxis of growth of small esophageal varices in cirrhosis.

Gastroenterology 127, 476-484

Merli M, Nicolini G, Angeloni S, Rinaldi V, De Santis A, Merkel C, Attili AF, Riggio O (2003): Incidence and natural history of small esophageal varices in cirrhotic patients. J Hepatol $\underline{38}$, 266-272

Mitra SK (1966): Hepatic vascular changes in human and experimental cirrhosis. J Pathol Bacteriol 92, 405-414

NIECSTEV; North Italian Endoscopic Club for the Study and Treatment of Esophageal Varices (1988): Prediction of the first variceal hemorrhage in patients with cirrhosis of the liver and esophageal varices. A prospective multicenter study. N Engl J Med $\underline{319}$, 983-989

Oh HJ, Park JM, Yoon SB, Lee HH, Lim C-H, Kim JS, Cho YK, Lee B-I, Cho Y-S, Choi M-G (2017): Bleeding After Endoscopic Procedures in Patients With Chronic Hematologic Thrombocytopenia. Dig Dis Sci 62, 746-754

Pagliaro L, D’Amico G, Pasta L, Politi F, Vizzini G, Traina M, Madonia S, Luca A, Guerrera D, Puelo A, D’Antoni A: Portal hypertension in cirrhosis: natural history; in: Portal Hypertension: Pathophysiology and Treatment; hrsg. v. Bosch J, Groszmann R; Blackwell Science, Oxford 1992, 72-92

Paquet KJ (1982): Prophylactic endoscopic sclerosing treatment of the esophageal wall in varices -- a prospective controlled randomized trial. Endoscopy $\underline{14}, 4-5$

Plentz RR, Malek NP, Deutsche Gesellschaft für Verdauungs- und Stoffwechselerkrankungen (DGVS) (2014): Neue Erkenntnisse aus der Leitlinien “Hepatozelluläres Karzinom”. Dtsch Med Wochenschr 139, 2529-2531

Propst A, Propst T, Zangerl G, Ofner D, Judmaier G, Vogel W (1995): Prognosis and life expectancy in chronic liver disease. Dig Dis Sci 40, 1805-1815

Pugh RN, Murray-Lyon IM, Dawson JL, Pietroni MC, Williams R (1973): Transection of the oesophagus for bleeding oesophageal varices. Br J Surg $\underline{60}$, 646-649

Radisavljević M, Bjelaković G, Jović J, Radovanović-Dinić B, Benedoto-Stojanov D, Brzački V, Marković-Živković B (2017): Creatinine-modified Child-Turcotte-Pugh score is a good predictor of a short-term survival in patients with bleeding from esophageal varices. Vojnosanit Pregl 74, 13-18

Riphaus A, Wehrmann T, Hausmann J, Weber B, von Delius S, Jung M, Tonner P, Arnold J, Behrens A, Beilenhoff U, et al. (2015): Update S3-Leitlinie "Sedierung in der 
gastrointestinalen Endoskopie" 2014 (AWMF-Register-Nr. 021/014). Z Gastroenterol 푸, $802-842$

Sabbà C, Ferraioli G, Buonamico P, Berardi E, Antonica G, Taylor KJ, Albano O (1992): Echo-Doppler evaluation of acute flow changes in portal hypertensive patients: flow velocity as a reliable parameter. J Hepatol $\underline{15}, 356-360$

Sarin SK, Lahoti D, Saxena SP, Murthy NS, Makwana UK (1992): Prevalence, classification and natural history of gastric varices: a long-term follow-up study in 568 portal hypertension patients. Hepatology 16, 1343-1349

Sauerbruch T, Wotzka R, Köpcke W, Härlin M, Heldwein W, Bayerdörffer E, Sander R, Ansari H, Starz I, Paumgartner G (1988): Prophylactic sclerotherapy before the first episode of variceal hemorrhage in patients with cirrhosis. N Engl J Med $\underline{319}, 8-15$

Schepke M, Kleber G, Nürnberg D, Willert J, Koch L, Veltzke-Schlieker W, Hellerbrand C, Kuth J, Schanz S, Kahl S, et al. (2004): Ligation versus propranolol for the primary prophylaxis of variceal bleeding in cirrhosis. Hepatology 40, 65-72

Shi X, Lin Y-P, Gao B, Zhang P (2017): Impairment of Hematopoietic Precursor Cell Activation during the Granulopoietic Response to Bacteremia in Mice with Chronic-Plus-Binge Alcohol Administration. Infect Immun 85, e00369-17

Shiratori Y, Imazeki F, Moriyama M, Yano M, Arakawa Y, Yokosuka O, Kuroki T, Nishiguchi S, Sata M, Yamada G, et al. (2000): Histologic improvement of fibrosis in patients with hepatitis $C$ who have sustained response to interferon therapy. Ann Intern Med 132, 517-524

Silvis SE, Nebel O, Rogers G, Sugawa C, Mandelstam P (1976): Endoscopic complications. Results of the 1974 American Society for Gastrointestinal Endoscopy Survey. JAMA $\underline{235}, 928-930$

Sommer CM, Stampfl U, Kauczor HU, Pereira PL (2014): Nationale S3-Leitlinie Hepatozelluläres Karzinom. Radiologe 54, 642-653

Tahan V, Canbakan B, Balci H, Dane F, Akin H, Can G, Hatemi I, Olgac V, Sonsuz A, Ozbay G, et al. (2008): Serum gamma-glutamyltranspeptidase distinguishes nonalcoholic fatty liver disease at high risk. Hepatogastroenterology $\underline{55}, 1433-1438$

Takuma Y, Nouso K, Morimoto Y, Tomokuni J, Sahara A, Toshikuni N, Takabatake H, Shimomura H, Doi A, Sakakibara I, et al. (2013): Measurement of spleen stiffness by acoustic radiation force impulse imaging identifies cirrhotic patients with esophageal varices. Gastroenterology 144, 92-101.e2

Tsochatzis EA, Bosch J, Burroughs AK (2014): Liver cirrhosis. Lancet $\underline{383}$, 1749-1761

WHO (2018a): Hepatitis-B fact sheet; http://www.who.int/en/news-room/factsheets/detail/hepatitis-b; Zugriff am 15.10.2018

WHO (2018b): Hepatitis-C fact sheet; http://www.who.int/en/news-room/factsheets/detail/hepatitis-c; Zugriff am 15.10.2018 
WHO 2014 Global status report on alcohol and health. (2014); apps.who.int/iris/bitstream/10665112736/1/9789240692763_eng.pdf; Zugriff am 14.10.2018

Wiesner R, Edwards E, Freeman R, Harper A, Kim R, Kamath P, Kremers W, Lake J, Howard T, Merion RM, et al. (2003): Model for end-stage liver disease (MELD) and allocation of donor livers. Gastroenterology 124, 91-96 


\section{Danksagung}

Für die Betreuung, sowohl im Rahmen der Datenerhebung als auch bei der Interpretation dieser Daten, sowie für kritische Anmerkungen bin ich Herrn PD Dr. S. Kunsch mit Dank verbunden. Für hilfreiche Kommentare danke ich Herrn PD Dr. Dr. A. Neeße. Mein weiterer Dank gilt Herrn Prof. Dr. V. Ellenrieder, der motivierend die Arbeit begleitete. Ein herzlicher Dank gilt außerdem meinen Kollegen, insbesondere Frau R. Masri, Frau Dr. J. Schöhl und Herrn Dr. N. C. Mechie. 


\section{Lebenslauf}

Als zweites von drei Kindern von Wilhelm und Cäcilia Hannemann wurde ich am 07. November 1982 in Einbeck geboren. Nach Besuch der Grundschule in Markoldendorf und der Orientierungsstufe in Dassel besuchte ich das Paul-Gerhard-Gymnasium in Dassel im Zeitraum von 1995 bis 2002. Zwischendurch verbrachte ich ein Jahr als Austauschschülerin in Perth in Australien im Schuljahr 1999/2000. Nach Erhalt des Abiturs fing ich im Jahr 2002 an der Georg-August-Universität in Göttingen das Medizinstudium an. In 2008 famulierte ich fünf Wochen an der Agostino-Gemelli-Klinik in Rom in der Gefäßchirurgie. Während des Praktischen Jahrs verbrachte ich zwei Monate an der Mount Sinai Klinik in New York im Bereich für Herz-Thorax-Chirurgie. Nach Erhalt der Approbation Ende 2008 fing ich am 01. März 2009 als Assistenzärztin in der Inneren Medizin des Krankenhauses in Witzenhausen an. Nach einem Jahr wechselte ich in die Abteilung für Gastroenterologie und Endokrinologie der Universitätsmedizin in Göttingen. Am 27. August 2010 heiratete ich Konstantinos Tsaknakis. Im Jahr 2011 rotierte ich für sieben Monate auf die kardiologisch geführte Intensivstation. Am 3. Januar 2013 wurde unser Sohn Philippos geboren, und ich ging für 14 Monate in Elternzeit. Nach Wiederaufnahme der ärztlichen Tätigkeit rotierte ich in die Sonographie und die Endoskopie der Abteilung. Zu dieser Zeit begann ich die Daten für die Promotionsarbeit zu sammeln. Seit September 2015 arbeite ich in Teilzeit mit einer auf 75\% reduzierten Arbeitszeit. Am 18. Mai 2016 freuten wir uns über die Geburt unserer Tochter Sophia. Im Dezember 2016 wurde ich zur Fachärztin für Innere Medizin. Seit Februar 2017 gehe ich weiter meiner Arbeit in der Abteilung für Gastroenterologie und gastrointestinale Onkologie der Universitätsmedizin Göttingen nach. 